\title{
Satellite Multi/Hyper spectral HR Sensors for mapping the Po- sidonia oceanica in South Mediterranean Islands
}

\author{
Flavio Borfecchia ${ }^{1}$, Carla Micheli ${ }^{2}$, Luigi De Cecco ${ }^{1}$, Gianmaria Sannino ${ }^{2}$ and Maria Vittoria Struglia ${ }^{2}$, Alcide Gior- \\ gio Di Sarra², Carlo Gomez ${ }^{3}$, Giuliana Mattiazzo ${ }^{4}$
}

1 External ENEA Collaborator; borfecchia@virgilio.it; gdececco@gmail.com.

2 ENEA, Italian National Agency for New Technologies, Energy and Sustainable Economic Development. Research Center Casaccia, via Anguillarese, 301, 00123 Rome, Italy; carla.micheli@enea.it; gianma-ria.sannino@enea.it; mariavittoria.struglia@enea.it; alcide.disarra@enea.it.

3 Cantieri Navali Esposito S.n.c., via Borgo Italia, snc. Pantelleria (TP), Italy; gomezpalomac@gmail.com.

4 Polytechnique University of Turin, Mechanical Engineering Dep. Turin Italy; giuliana.mattiazzo@polito.it.

* Correspondence: borfecchia@virgilio.it ( F. B.); carla.micheli@enea.it (C. M.)

\begin{abstract}
The Mediterranean basin is a hot spot of climate change where the Posidonia oceanica (L.) Delile (PO) and other seagrass are under stress due to its effect on marine coastal habitats and the rising influence of anthropogenic activities (i.e. tourism, fishery). The PO and seabed ecosystems, in the coastal environments of Pantelleria and Lampedusa, suffer additional growing impacts from tourism in synergy with specific stress factors due to increasing vessel traffic for supplying potable water and fossil fuels for electrical power generation. Earth Observation (EO) data, provided by high resolution (HR) multi/hyperspectral operative satellite sensors of the last generation (i.e. Sentinel 2 MSI and PRISMA) have been successfully tested, using innovative calibration and sea truth collecting methods, for monitoring and mapping of PO meadows under stress, in the coastal waters of these islands, located in the Sicily Channel, to better support the sustainable management of these vulnerable ecosystems. The area of interest in Pantelleria was where the first prototype of the Italian Inertial Sea Wave Energy Converter (ISWEC) for renewable energy production was installed in 2015, and sea truth campaigns on the PO meadows were conducted. The PO of Lampedusa coastal areas, impacted by ship traffic linked to the previous factors and tropicalization effects of Italy southernmost climate change transitional zone, was mapped through a multi/hyper spectral EObased approach, using training/testing data provided by side scan sonar data, previously acquired. Some advanced machine learning algorithms (MLA) were successfully evaluated with different supervised regression/classification models to map seabed and PO meadow classes and related Leaf Area Index (LAI) distributions in the areas of interest, using multi/hyperspectral data atmospherically corrected via different advanced approaches.
\end{abstract}

Keywords: Posidonia oceanica (PO), LAI \& density; PO health \& Pergent model; sea truth collection; Earth Observation; HR satellite multispectral/hyperspectral sensors; atmospheric correction; coastal monitoring; mapping shallow waters habitat seabed; Calibration/validation \& training/test; Classification \& regression Machine Learning; Model Performance \& thematic Accuracy; Sentinel 2 MSI multispectral \& PRISMA hyperspectral; ISWEC(Inertial Sea Wave Energy Converter)

\section{Introduction}

In the Mediterranean, Posidonia oceanica (PO) is one of the most important seagrass carbon sink species for the variety and extension of its meadows, but it is increasingly at risk and sometimes in decline, with the frequent reduction of its extent and an increase in meadow fragmentation $[1,2,3]$. This arises from the variations in sea water parameters (i.e. turbidity, temperature, acidity, salinity) linked to climate change and impacts from anthropogenic activities (fishing, traffic of ships and oil tankers, new coastal 
infrastructures) with coastal habitat modifications even favorable to tropical alien species invasion $[4,5,6,7]$. Like other seagrasses, PO plays a role of paramount importance in coastal habitats worldwide, providing ecological goods and ecosystem services that contribute to human welfare and shoreline protection [8]. To evaluate the ecological status of PO meadows, different approaches have been developed using also the relationship between their genetic/genotypic diversity $[9,10]$ and the main biophysical parameters (i.e. shoots density, LAI) that today can be effectively monitored and mapped using integrated approaches based on remote sensing techniques [11].

The recent advances in Earth Observation (EO) applications, based on satellite and airborne platforms [12], provide operative tools for supporting extensive monitoring needs for sustainable management of sea/inland waters $[13,14]$ and agri-ecosystems, natural and managed [15, 16], in various environments of the Earth's surface [17, 18]. However, EO based monitoring of shallow waters and seabed of the coastal environment characterized by anthropogenic impacts, still represent a challenge, due to coastal water turbidity often associated with various atmospheric effects and noises, joined with the difficulties of in situ sampling for collecting sea truth calibration data of submerged plants on seabed by means of scuba diving. These are important limiting factors to useful exploitation of EO High Resolution (HR) data for extensive mapping of PO and coastal seabed and water quality parameters [14, 19], especially where the coastal sea currents are significant like in the Southern Mediterranean islands, with consequent additional signal degradations from increased water turbidity from sediment resuspension and sun glint presence $[19,20,21,22]$.

The Italian islands of the southern Mediterranean, like Pantelleria and Lampedusa, generally present transparent coastal waters and PO meadows, with seabed habitats that still exhibit significant levels of biodiversity and specific adaptation to the accentuated energy levels of sea waves that characterize this area of the Sicily Channel [2, 20]. This aspect favored the installation of the first Italian Inertial Sea Wave Energy Converter (ISWEC) there, choosing Pantelleria as a representative of many small-islands in the Mediterranean Sea, whose energetic independence through eco-compatible innovative solutions can improve the lives of the isolated coastal communities while safeguarding their coastal fragile ecosystems from the perspective of global sustainability [23].

Despite their shallow water wealth and natural heritage, often safeguarded in protected areas, the actual increase in anthropogenic activities, linked to tourism and fishing, negatively impacts on these natural ecosystems, with consequent potential damage and a need for more effective monitoring to support their sustainable management. Other threats derive from the difficulties of supplying potable water and electrical power to many islands not connected to the national electricity grid, where additional factors of environmental impacts come from the traffic of boats carrying fossil fuels for local electricity production, also used for desalinization of sea water [24].

In order to provide eco-compliant electric power from renewable resources, in 2015, the ISWEC prototype was installed for testing purposes in the coastal area offshore of Pantelleria. Even designed to minimize the impacts, the prototype installation and operation involved interactions with local PO and seagrass meadows, with possible plant damage and water transparency decreasing due to seabed sediment resuspension [25, 24].

Thus, the effective monitoring of the local PO ecosystems in the two islands is recommended in order to allow the detection of potential stress and damage linked to the increase in anthropogenic activities mentioned above and/or other natural factors. In 2015 and 2016, two measurement campaigns were carried out in the vicinity of the ISWEC proto-type for collecting sea truth data on PO meadows [24, 26].

Satellite EO-based approaches for PO and seagrass monitoring can be very effective, but they must be based on suitable HR sensors, as well as effective atmospheric preprocessing and calibration based on appropriate in situ measurements. Once suitably corrected for atmospheric noise, the satellite HR EO techniques can provide effective multiscale tools for monitoring marine ecosystems on shallow water seabed. However, the 
basic requirements for characterizing the PO meadow and sub-merged habitats of shallow waters and their distribution patches at the "land-sea" inter-face area, in optically complex coastal waters, first focus mainly on remote HR sensors within the 30-10 m a.g.r. (above ground resolution) and suitable radiometry, sensible to weak signals coming from the coastal seabed $[21,20]$. In recent years, various satellite sensors have started to provide EO data with these features for EO applications, like multispectral Landsat 8 OLI by NASA and Sentinel 2 MSI (of the Copernicus ESA EU program), or the most recent hyperspectral PRISMA, implemented by ASI (Italian space agency), having different additional capabilities based on its 240 acquisition bands, to be checked for these specific coastal monitoring applications. These sensors, compared to previous ones of the same family, in addition to the increase in the acquisition bands in the visible and TIR, present improvement in their radiometry that offer greater capacity for operational monitoring of coastal ecosystems previously unavailable [19]. In particular, the PRISMA sensor makes available the opportunity to test this satellite EO hyperspectral technique in this specific sector, where airborne remote sensing techniques have been mostly used.

Since atmospheric noise can greatly affect the useful reflectance signals exiting from the water surfaces, the radiometric preprocessing must include an effective atmospheric correction to remove, in particular, the significant contribution from the aerosol load and other factors typical of the water column at the sea-land interface [20, 27, 28]. In addition, the necessary sea truth measurements, devoted to quantitative PO characterization, are expensive and labor-intensive due to human and instrumental resources needed to operate during diving for sample collection and subsequent laboratory analyses.

Considering these limiting factors, in this work, original EO-based monitor-ing/mapping methods for the useful exploitation of information extracted from the necessarily exiguous number of available in situ measurement stations were implemented. The developed approach allowed us to exploit the radiometric variability related to EO data of the entire sampling area $\left(\sim 50 \mathrm{~m}^{2}\right)$ of Pantelleria stations, within a calibration/validation schema for the regression models, based on some machine learning regression algorithms (MLRA), designed to be robust against possible outliers and incomplete/limited samples $[29,30,31]$.

Recently, machine learning/artificial intelligence (AI) computer applications have increasingly gained more popularity, especially in sectors where there is a need to make effective predictions or trends calculations in case of limited/incomplete calibration/training data, statistical noise or collinearity presence, taking advantage of the so-called increasing Big Data availability and robust statistical modelling advances. One of them refers to re-mote sensing EO applications, where the increase in spectral/spatial capabilities of the new sensors on board of the operative satellite platforms provides an unprecedented amount of EO data, continuously upgraded and made available online to the users $[18,32]$. On the other hand, in EO based monitoring and modelling applications, the frequent necessity to face growing costs and resources to collect expensive in situ data reduces the possibility to plan a calibration as ample and complete as needed and desired. Machine learning algorithms (MLAs) and schemas were developed to more effectively exploit this kind of incomplete information through their self-adapting and learning capacities for useful predictive modeling with suitable assessment of mapping functions from inputs, even limited, to outputs, optimized function approximation, or classification [32]. In particular, they focus on two typical main usages of EO data processing, involving the classification and regression approaches [29]. The classification aims at predicting a discrete class of output labels from input data (typically, EO data as atmospherically corrected multi/hyperspectral reflectance responses), after a learning phase termed training. The regression is instead aimed at predicting continuous quantities on the basis of input (the EO data) and a function model obtained from a calibration set of input/output data. To support the development of a methodology for monitoring and mapping the PO habitats in these islands, various typical MLA were preliminarily considered for regression (MLRA) modeling and supervised classification (MLCA) of the multi/hyperspectral data, 
taking into account their different capabilities and performance in various situations of noise, limited class samples, and outlier presence in input data that frequently occurs in EO applications for coastal marine monitoring [26, 30, 33].

According to previous works, these satellite remote sensing HR techniques were combined with in situ point measurements of biophysical parameter to monitor and map the PO meadows and benthic habitats in the shallow coastal waters of the Pantelleria and Lampedusa islands [34, 35].

Starting from the in situ measurements of the density and LAI (Leaf Area Index) of $\mathrm{PO}$, estimated for the sampling station areas in proximity of the ISWEC installation, various distributions of these important biophysical parameters were assessed in the coastal shallow waters of Pantelleria, using regression models based on different MLRA algorithms and the original calibration/validation schema with Sentinel 2 MSI multispectral data $[36,37]$.

According to Pergent [38], the developed methodology included the assessment of the health distribution of $\mathrm{PO}$ located along the entire coast of Pantelleria island, using bathymetry and the EO-derived PO density distribution.

The distribution of PO meadows and other seabed classes of the Lampedusa coast were estimated through PRISMA hyperspectral data by means of an advanced MLCA and supervised classification scheme, using the side scan sonar data, available for the western part of the coastal seabed [39], as the training/validation set [40,41].

The ENMAP (Environmental Mapping and Analysis Program) software box package was used for both regression and classification tasks, based on learning machine algorithms [37]. This software is integrated into the free and open-source widely distributed QGIS and was developed in the framework of the German hyperspectral EO HR mission, with the launch of the satellite mission expected in the next few months and a sensor similar to the operative PRISMA by ASI (Italian Space Agency). The PRISMA data, distributed as hdf5 format files, was decoded using the PRISMAREAD package, working in the R statistic environment [42].

\section{Materials and Methods}

\subsection{Methodology}

In the developed methodology, the S2 and PRISMA EO data, preprocessed using different atmospheric correction options, available through the packages considered (ACOLITE, ICOR, System Pre-processors of EO Data provider), were exploited for assessing regression/classification models, based on sea truth independent data and MLA, whose effectiveness was assessed by means of a performance metric using various statistic parameters. In such a way, at the same time, both the atmospheric correction effectiveness and algorithm suitability were evaluated. The most performant models were then used for the production of the final thematic maps of seabed classes and biophysical parameter distributions of $\mathrm{PO}$ on which are based the intercomparisons and considerations at different scales, referring to the anthropogenic and natural impact factors.

\subsection{Areas of interest and $E O$ data}

The EO techniques for estimating the concentrations of the various optically active constituents of the shallows waters and monitoring submerged plant, make widely use of the multispectral data currently provided by HR and VHR (High and Very high spatial resolution) satellite/airborne sensors with resolutions respectively from a few tens of $m$ up to sub-metric (QuickBird, WorldView 2, Dedalus ATM,...). The VHR satellite systems operate on user request and in a non-systematic way, with frame areas of about 10X10 $\mathrm{Km}$, more suitable for local and not operational monitoring with limited space-time coverage. Thus, to provide support for more operational monitoring needs, in the 2013 the new polar HR sensor Landsat 8 OLI (Operational Terra Imager), started to provide systematically multispectral images $\left(180 \times 180 \mathrm{~km}^{2}\right)$ of the earth's surface with $30 \mathrm{~m}$ of a.g.r. 
resolution, made continuously available to the users in repositories, accessible online. This sensor, compared to previous ones of the same family, in addition to the increase in the number of acquisition bands in the visible and TIR (Thermal Infrared), presents improvements in its radiometry that offer greater capacity for operational monitoring of coastal ecosystems previously unavailable. In addition to the usual spectral bands, a new "coastal" acquisition channel have been introduced in the higher frequencies of blue, to improve its coastal monitoring capabilities at the spatial resolution of $30 \mathrm{~m}$. most profitable in coastal and inland waters, often optically complex. In 2015, ESA (European Space Agency) launched on board of Sentinel 2 (S2) polar satellite the MSI (MultiSpectral Instrument) sensor, able to acquire data at $10 \mathrm{~m}$ a.g.r., and providing $\mathrm{EO}$ data open to scientific user and application, with improved revisiting capability of 5 day, based on the twin platform, Sentinel 2 B, that became operational shortly after the first one. In the 2019, the hyperspectral sensor PRISMA (240 acquisition bands) by ASI (Italian Space Agency) became operational and with its capability of many acquisition channels in the visible range, at 30 $\mathrm{m}$ of a.g.r., currently represents an unprecedented opportunity even for the applications in the coastal monitoring sectors.

The 10-m multispectral HR data, provided by the S2 MSI satellite sensor, including the entire coastal areas of interest, were acquired and preprocessed, with the objective to test their improved monitoring capabilities of PO distribution with the related LAI (Leaf Area Index) and other biophysical parameters. Furthermore, the hyperspectral data in the VIS-NIR (Visible - Near Infrared) range $(470-970 \mathrm{~nm}$ ) at $30 \mathrm{~m}$ of a.g.r. (above ground resolution) provided by PRISMA, have been tested for mapping the PO meadows and seabed in the coastal shallow waters of Lampedusa.

The monitoring activities in Pantelleria were primarily focused on the area of the ISWEC installation but with the perspective to test the spatial extensibility of calibration, carried out in the proximity of the converter (visible within the sampling station 1 borders in the figure 1), over remaining coastal areas of the island.

The figure 1 shows the Pantelleria island image in true color acquired by S2 on 2008-2015 (upper part), with the detailed area of interest (lower part) including the sampling station areas indication and global localization map (lower right corner). The ISWEC prototype is visible in the area of sampling station $n$. 1 . The detailed image shows also the sea waves perturbing the water surface with sun glint and sediment suspension that introduce noises to the useful EO reflectance signals from seabed and shallow water.

Considering also the lower size of Lampedusa (Figure 2), the EO derived map of its PO meadows and other seabed main classes, has been produced for the coasts of the entire island, using the partial distribution obtained through side-scan sonar as training/validation. 


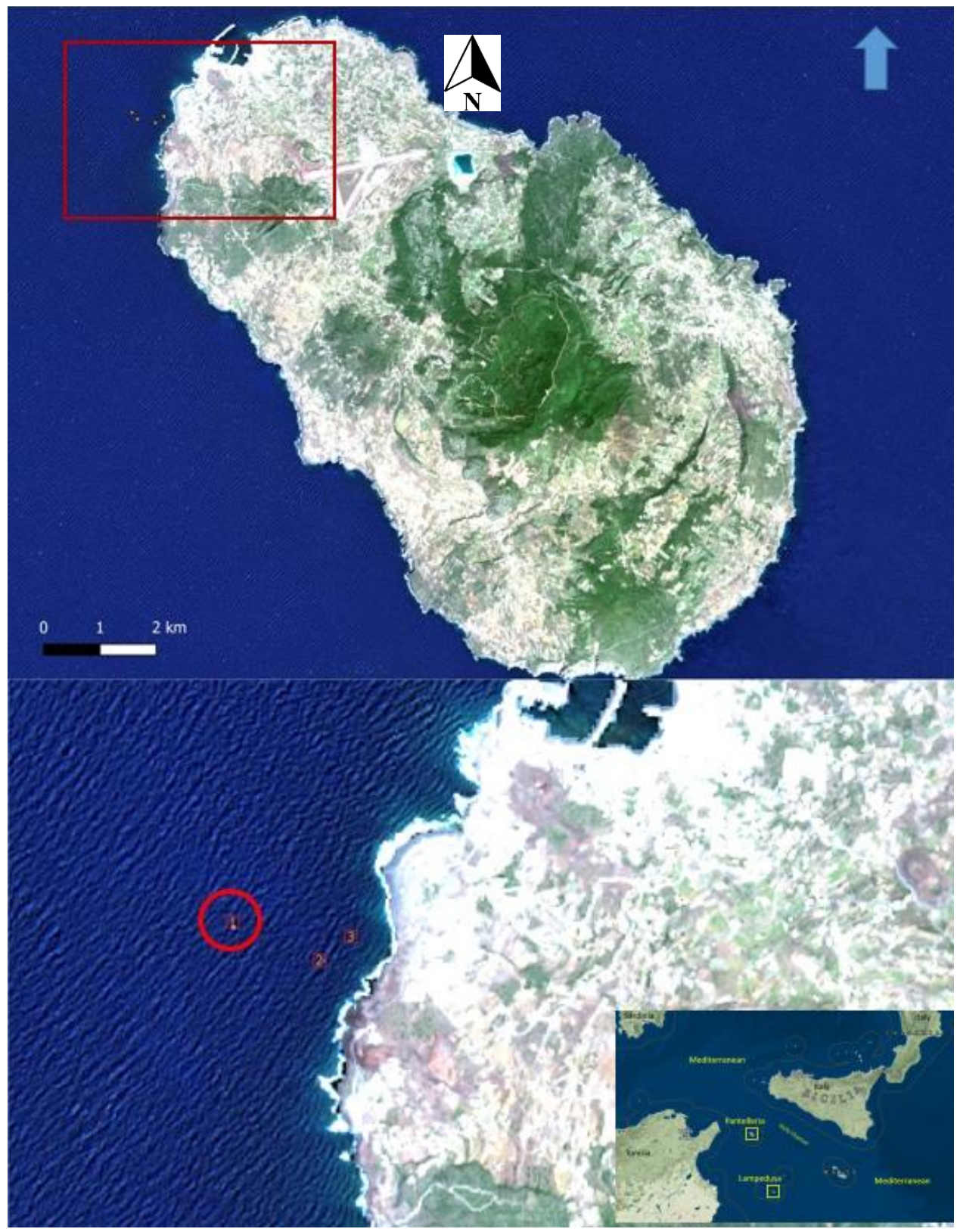

Figure 1 - Pantelleria island in the S2 frame acquired on 20-08-2015, reported in true color (R:665 $\mathrm{nm}, \mathrm{G}: 560 \mathrm{~nm}, \mathrm{~B}: 490 \mathrm{~nm})$. In the upper image of the entire island, the area of interest including the ISWEC location with the four sampling station of 2016 sea truth campaign, is indicated by the box de-limited by red lines. The image at lower half shows the detail of the area of interest with the three sampling stations of the 2015 campaign and the location of ISWEC converter (in the red circle) enclosed in the station n. 1 area. The synoptic map, with location of the islands of interest in the Sicily channel of Mediterranean, is also provided (lower right corner).

The position of the converter was chosen on the basis of the energy distribution of wave motion along the coasts of the island, evaluated through oceanographic modeling and multi-temporal data appropriately acquired at adequate resolution, it is located within areas where there are sparse PO meadows that need to be monitored to highlight any consequent potential threats. 


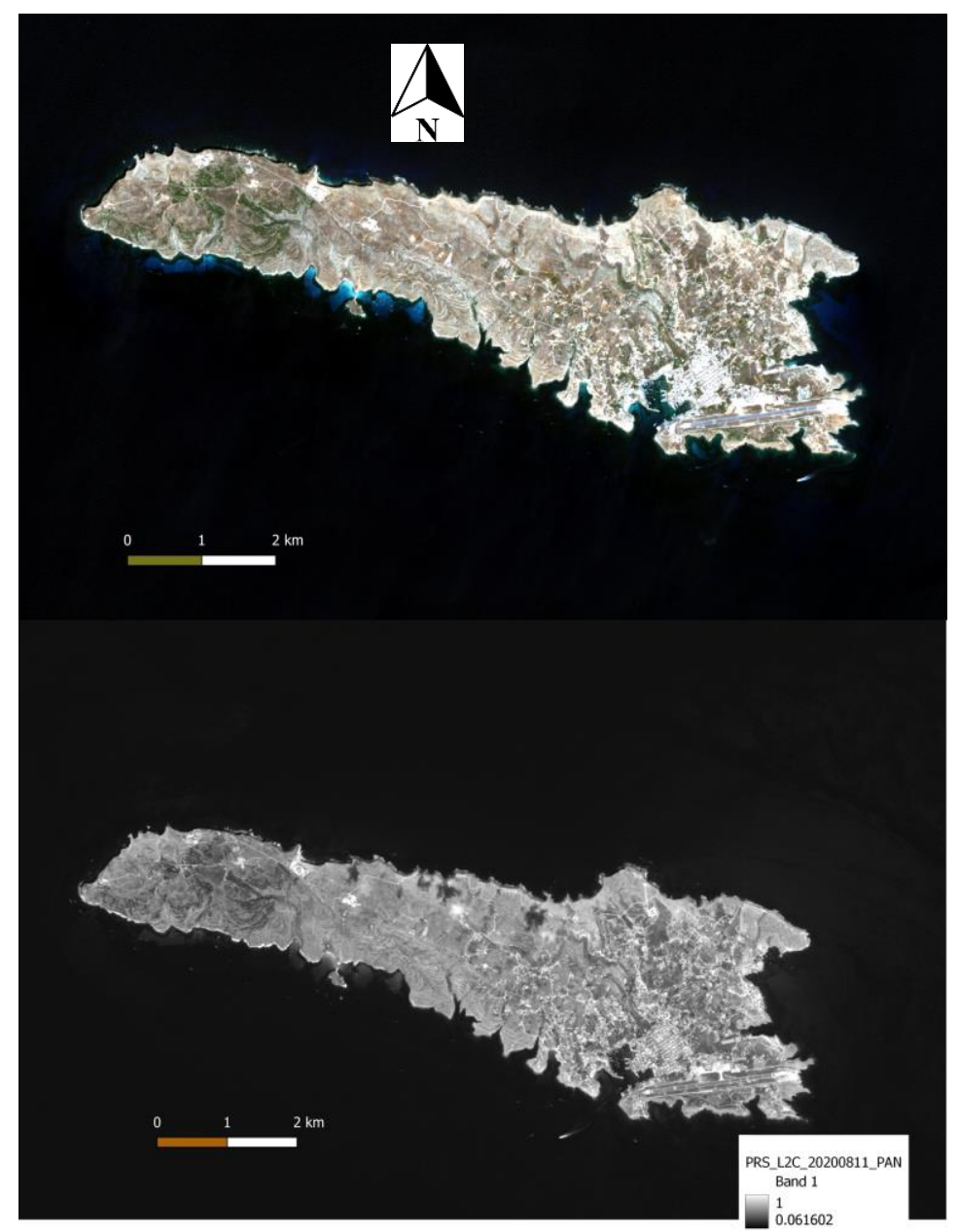

Figure 2 - Lampedusa island (True color RGB) as seen by S2 MSI (10 m a.g.r.) multispectral sensor (upper) on the 17-08-2015 and by PRISMA hyperspectral sensor on 11-08-2020 (panchromatic channel at $5 \mathrm{~m}$ a.g.r.).

\subsection{Sea truth}

In general, the sea truth surveys for the assessment of $\mathrm{PO}$ focus mainly on the characterization of meadows with continuous distributions (cover $>60-80 \%$ ), without any optimization aimed at providing an area-based effective calibration for modelling based on EO data. In case of discontinuous, fragmented, and patchy distributions of PO meadows, the in situ calibration for the extensive distribution estimate of their biophysical parameters through EO data, should require the assessment of the entire local area of interest, including the sub-areas lacking plants, with a mean cover percentage lower than $20 \%$ that must be accounted for. To address this limiting factor, an original methodology has been exploited here for the sea truth acquisition of calibration measurements on the fragmented PO meadows near the ISWEC installation in Pantelleria based on a systematic sampling scheme. To better deal with PO patchy distribution, an on-purpose implemented sampling method was exploited that allowed the estimation of a percent cover parameter using a semiautomatic digital procedure, from digital images of measurement plots acquired by scuba. The estimated cover parameter was then exploited for refining the in situ LAI distribution assessment, more area than meadow oriented, with the specific objective of improving EO calibration [24, 26].

The ISWEC prototype was installed in late July-early August 2015, and the first sea truth campaign was carried out in the second half of August, while the second one started in the middle of October of the following year. During the campaigns, various measurements of several biophysical parameters related to PO phenology have been acquired, in 
correspondence with sampling stations distributed along the bathymetric negative gradient, starting from the converter prototype location, at $31 \mathrm{~m}$. of depth (fig 3). Three measurement stations in 2016 were located at the same coordinates as those exploited in 2015, while the fourth was positioned between the last two, at about $30 \mathrm{~m}$. of bathymetry. Some GPS techniques and other auxiliary instrumentation (i.e. compass, underwater digital photo camera, containers for plant samples), used in diving supported information collection of in situ biometric measurements completed with the subsequent laboratory analyses for the assessment of the biophysical parameters of interest (biomass, shoot density, cover, LAI). The work in the field, consisting mainly of the underwater activities using the $1 \mathrm{~m}^{2}$ sampling frame (Figure 6) and auxiliary instrumentation, took place respectively in the second half of last August and in the middle of October, according to logistic and organization constraints and weather/sea conditions. In the perspective of EO based regression model calibration and in accordance with the most popular protocols, for each measurement station, a systematic sampling scheme based on $1 \mathrm{~m}^{2}$ plots was exploited (Fig. 3). The measurement stations are identified by their respective GPS center coordinates on the surface and are associated with the related plots, each of $1 \mathrm{~m}^{2}$, where the biophysical measurements and samples were collected using an oriented frame with the objective of allowing the characterization of an area compatible with the a.g.r resolution of satellite images. The station coordinates coincide with those of plot $\mathrm{n} .1$ center, while the $\mathrm{d}$ parameter of the plot scheme was set at $25 \mathrm{~m}$, in order to cover a square area of about $50 \mathrm{~m}^{2}$, corresponding to the $5 \times 5$ pixel of the S2 MSI sensor. In addition, RGB digital images of plots, taken with a special underwater camera, including approximately the frame with a defined orientation, were acquired to support the development of a robust, innovative and semi-automatic procedure for estimation of more reliable coverage/density values (see below). Various phenology parameters of $\mathrm{PO}$ were visually assessed within each plot identified by a North-oriented white frame (Fig 3), whose photograph image was taken preliminary to other diving measurement activities. The density was appraised by visually counting the number of shoots $\left(\mathrm{shoot} / \mathrm{m}^{2}\right)$ in the North-West quadrant of the sampling frame. Some PO plant samples (3-5 shoots) were then collected from the North-West quadrant of the frame and properly stored for the successive laboratory analyses. Consequently, by applying the conventional protocol, the average density was calculated and expressed in the number of shoots $/ \mathrm{m}^{2}$ for the whole station area. The laboratory analyses provided the characterization of phenology (i.e. LAI) and physiological parameters of $\mathrm{PO}$ samples, such as biomass (fresh and dry weight) and biometry, together with genetic polymorphism for the determination of the genetic structure of the meadows (These genetic and others aspects will be widely discussed within another paper in preparation). The most common protocols for estimating the coverage of the PO meadows in diving are based on the visual evaluation of the percentage coverage of $\mathrm{PO}$ within a plot sample area. 
St. 1: Lat: $36^{\circ} 49^{\prime} 23^{\prime \prime} \mathrm{N}$, Long : $11^{\circ} 55^{\prime} 13^{\prime \prime} \mathrm{E}$ (ISWEC)

st. 2: Lat: $36^{\circ} 49^{\prime} 21^{\prime \prime} \mathrm{N}$, Long: $11^{\circ} 55^{\prime} 25^{\prime \prime} \mathrm{E}$

st. 3: Lat: $36^{\circ} 49^{\prime} 20^{\prime \prime} \mathrm{N}$, Long: $11^{\circ} 55^{\prime} 35^{\prime \prime} \mathrm{E}$

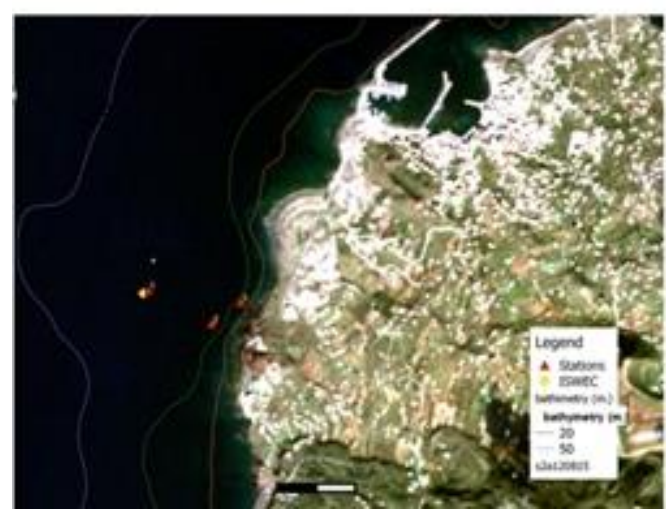

Sampling schema

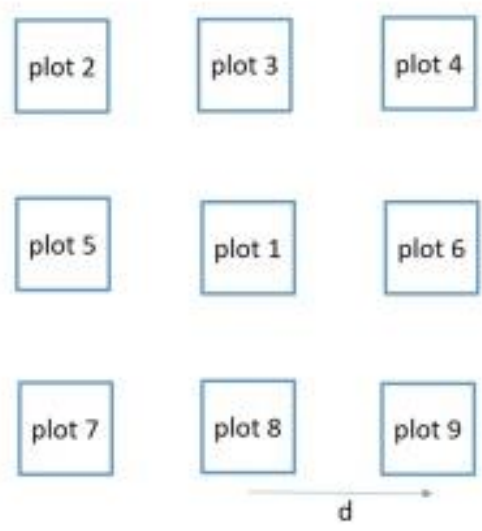

Figure 3- Location of the 3 stations and sampling scheme used for the survey campaign on the PO meadows at the installation site of the ISWEC prototype (left part). Sampling schema for sea truth collection (right part).

This estimate is likely always affected by approximations due to the subjectivity of the operator, further worsened by uneven lighting situations and various limitations related to underwater operating modes. The use of digital images of the area of interest at adequate resolution, duly oriented and pre-processed, allows areal assessment through semi-automatic operating procedures aimed at increasing repetitiveness and the reliability of the assessed cover values. Some digital pre-processing procedures, on purpose developed for both radiometric (normalization for illumination unevenness) and geometric (perspective and frame rectification/overlay) corrections of the acquired image of the station plots (fig 4), were applied before we proceeded with a supervised segmentation/classification algorithm. The classification output, without subjective photointerpretation, allowed us to appropriately segment the pre-processed image into three classes consisting of $\mathrm{PO}$ (green), sea bottom (blue) and frame (Fig. 4 bottom right), from which it is possible to easily derive the coverage percentage of the PO. The procedure developed was then applied to the entire set of plot images acquired for each sampling station.

At the ENEA Casaccia laboratory, Biomass and Biotechnology for Energy, the biometry of each plant (number, length, and width of the collected leaves) was also estimated, and the biomass was calculated in both fresh and dry weight after drying at $70^{\circ} \mathrm{C}$ for 72 hours, both in the epigeal (foliar) and rhizome. Once removed from the plants, the young leaves were previously washed in distilled water, removing the epiphytes, placed in liquid nitrogen and stored at- $80^{\circ}$ for the subsequent analyses. The density distribution of the $\mathrm{PO}$ (shoots $/ \mathrm{m} 2)$ at station level was derived by averaging the values assessed in diving on its plots.

Following the well established methods, the LAI and other parameters, at the level of the single stations, were calculated by averaging the laboratory biometric measurements of samples collected at plot level (i.e. PO leave areas and number of leaves per shoot, wet/dry specific weight) and related density values, with final normalization accounting for plot surface. 

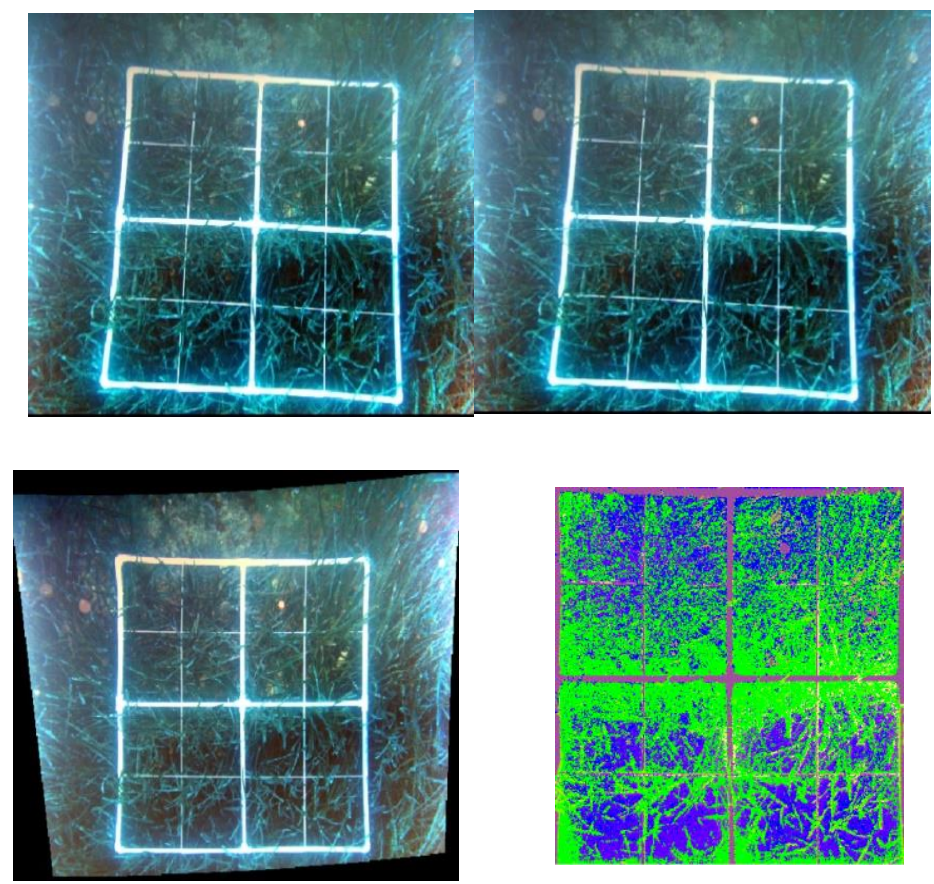

Figure 4 Use of the sampling frame on the PO meadows. Original image (top left) and after digital corrections to minimize the effects of uneven lighting (top right). Corrected image for perspective geometric distortion effects (bottom left) and classified using a semi-automatic procedure for identifying the PO coverage (bottom right)

The percent cover, obtained from digital processing of frame imagery taken while diving, was then introduced as a multiplying correction factor aimed at the optimization of the calibration of the regression modelling approaches based on EO data (see next chapter).

In 2016, the PO meadows of Lampedusa (western part) were preliminarily mapped using side-scan sonar on board a ship [39]. In addition to seabed classes of PO, some others related to differently grained sand and rock were also discriminated (Fig. 5). Given the scarce sonar detection capability of low density seabed vegetation, in addition to suitably detected PO, a sparse (potential) PO class was introduced too. The three classes of differently grained sand and dunes, discriminated by sonar acoustic waves due to their textures not easily detectable in EO data, were grouped into just two. According to the historical maps, the most reliable part of this achieved data was used for training/validation of MLCA (see next chapter), in the form of stratified randomly selected points extracted for the seven seabed classes.

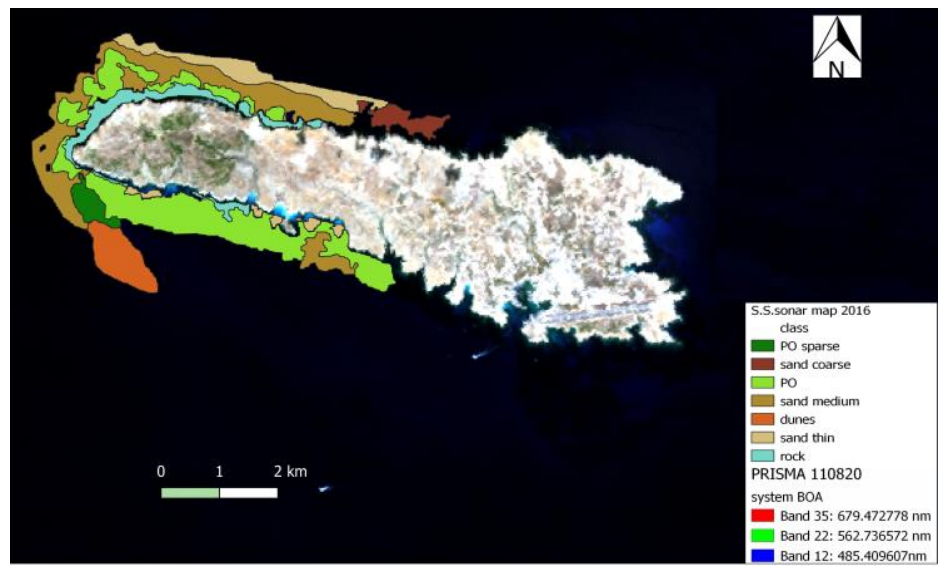


Figure 5- Side scan sonar map used for training /validation of machine learning classification models. The map is in overlay to true color hyperspectral PRISMA, frame acquired on the 11-08-2020 and atmospherically corrected (BOA).

\subsection{EO data processing and calibration}

The available EO frames, compatible with the sea truth data, were first selected on the basis of visual inspection, checking the presence of cloud cover and water turbidity patterns in the areas of interest. The selected data, atmospherically corrected using the different options, was then exploited in the MLRA and MLCA modelling approaches based on the sea truth calibration/training sets and using the various MLA algorithms. In the end, the final choice in terms of frame, pre-processing options, and MLA combinations, was accomplished on the basis of the performance parameters assessed in the model validation/accuracy assessment steps.

\subsubsection{Atmospheric pre-processing}

The general approach to water applications, based on the near infrared (NIR) reflectance channels for characterizing atmospheric aerosol parameters (i.e. aerosol optical depth as AOD) distributions, in case of shallow water, typical of oligotrophic open oceans, has proven to be less effective for monitoring shallow-water environments and seabed, including seagrass and PO coastal ecosystems [43]. In fact, coastal waters are rarely oligotrophic due to their frequent optical complexity, with high concentrations of various optically active substances (case II waters), which is often accentuated by sediment suspension dispersed in the water column, in the form of total suspended matter (TSM) concentration, which is increased by sea waves and currents. To properly address these difficulties in coastal water remote sensing, our approach includes atmospheric correction mainly accomplished using the current version of the ACOLITE package, specifically designed for atmospheric correction of multispectral remote sensing data at decametre resolution, for monitoring applications in coastal or inland waters, even with non-negligible turbidity [43]. It preliminarily starts with aerosol DSF fitting and system correction to produce a BOA (Bottom Of Atmosphere) reflectance distribution (without taking into account the detailed distribution of aerosol effects), then the corresponding WLR (Water Leaving Radiance/Reflectance) is assessed (taking into account the detailed aerosol effect distribution), if the retrieved aerosol distribution (AOD) reaches a sufficient noise level to degrade the water reflectance responses [45]. The package also provides the subset function of area of interest, automatic selection of water surfaces (WLR option) and the sun-glint removal from the processed multispectral data. This capability is remarkably favourable if we consider also the turbidity of the waters due to the accentuated hydrodynamics of the marine area of Pantelleria, caused both by the morphology of its coastal seabed and by the relevant intensity of the sea current field, which, especially in summer, characterizes this area of the Strait of Sicily. This aspect constitutes a limiting factor in the selection of exploitable satellite acquisition frames for the monitoring of its shallow waters, which, in summer, are considerably few, due to the presence of excessive diffuse turbidity and significant sun-glint effects (figure 1).

The radiometric correction for quantitative monitoring of the coastal seabed where the PO plants grow, in addition to atmospheric AOD, must take into account additional noise contributions from other factors, like water column and adjacency effects [46, 47]. Given the normal situation of water limpidity along these islands' coasts in case of current minima, the selection of the few frames without visible turbidity pattern affecting the areas of interest is assumed to guarantee negligible water column attenuation noises. Adjacency effects result from contamination of water reflectance signals of interface pixels (frequently including useful signals from PO plants) from contiguous land areas, depending on atmospheric scattering and AOD [47]. Thus, for intercomparison purposes, another 
atmospheric correction package, named ICOR [48], not specifically devoted to water applications, is also exploited. The code is able to produce BOA distribution, including this radiometric correction, not performed by ACOLITE (i.e. adjacency). The ACOLITE code is based on the Dark Spectrum Fitting (DSF) algorithm for the optimized estimation of the reflectance of coastal and inland waters, even with non-negligible turbidity, with optional correction for sun-glint effects. In essence, DSF, instead of assuming a negligible signal over water in predefined NIR or SWIR bands, and some spatial extent of aerosol type and concentration, aims to achieve spatial-spectral modelling by choosing the optimal bands for a given image or subset of images. Recent studies have found good performance of the DSF algorithm in optically complex coastal or estuarine waters [44].

To test the capabilities of the S2 MSI satellite sensor for mapping the PO meadows in the shallow waters of the island of Pantelleria, various multispectral frames taken in 2015 and 2016, at different levels of pre-processing, referring to different seasonal periods, have been first selected on the basis of both cloud coverage and turbidity patterns from sea current intensity.

For the atmospheric correction, the used approach was the so-called "image-based" that exploits the specific information contained in the same multispectral image to be corrected and does not require further in situ measurements in the field simultaneous with the satellite passage. Moreover, being easy to apply, it is suitable for our operational use.

In general, the $\mathrm{S} 2$ frames are available at two atmospheric basic pre-processing levels, termed TOA (Top Of Atmosphere) and standard atmospheric correction (performed through the Sen2Cor default processor), used for retrieving bottom atmosphere surface reflectance (BOA), without any refinement specifically devoted to suitably retrieving WLR. The latter includes both the contribution of optically active components in the water column, mainly including sediments (TSM) and CDOM (Coloured Dissolved Organic Matter) in addition to phytoplankton, as well as that relating to the coverage of the shallow seabed, coming from seagrass, macro-algae and various benthic substrates. To provide WLR distribution, more appropriate for our application, the ACOLITE package, recently made available in its last version among the open-source scientific codes, was introduced. ACOLITE code was designed to be specifically applied for atmospheric correction in coastal and inland water EO monitoring applications and provides corrections for sun-glint with the production of both BOA and WLR corrected reflectance distributions (only in case of aerosol presence), with automatic detection of water surface, but it doesn't include the adjacency effect removal.

Therefore, the radiometric correction of the selected frames for atmospheric effects was carried out also through the ICOR code integrated into the SNAP ESA (European Space Agency) package, which is not specifically conceived for pre-processing water surface imagery but is able to correct reflectance signals for adjacency effects. This last correction could be very important for the effective monitoring of the coastal shallow waters at the land-sea interface, due to the possible contamination of the upper reflection values by the contiguous earth zones. In this context, given the unavailability of processing tools able to do all the radiometric corrections above cited, it was introduced to allow a comparison of the relative weights of the different noise effects.

Considering the spectral ranges useful for water penetration and land-water discrimination, the PRISMA hyperspectral data in the 411-708 $\mathrm{nm}$ range ( 38 bands) has been selected preliminarily from its VIS-NIR dataset (66 bands) for the modelling step. Then they were used as they had been provided, directly under the form of BOA, without any water surface optimization and adjacency/sun glint effects removal, due to the unavailability of devoted processing packages. The classification carried out using the MLCA and the information from the multiple PRISMA bands, in addition to the distribution of the seabed classes, allowed a reliable estimate of the relative probabilities and levels of confidence of the result, with the possibility of using a threshold for the effective selection of the unclassified areas. 


\subsubsection{Modelling and classification}

The pre-processed S2 multispectral images were first exploited for assessing the distribution of PO biophysical parameters near the ISWEC converter of Pantelleria, using different MLRA and sea truth calibration data collected in correspondence with the measurement stations.

The objective of regression is to forecast a target value based on independent predictors under the hypothesis of a cause/effect relationship function model between variables, to be estimated using suitable known input-output values as a calibration data set. Regression techniques mostly differ based on the number of independent variables and the type of relationship between the independent and dependent variables. The widely diffused linear regression works well in the case of linear relationships and an optimal calibration set, but in the case of model functions not known and different from linear dependence with a lacking calibration set, the results can be unsatisfactory. This situation is typical of EO based monitoring applications, especially in shallow waters and coastal seabed habitats, where the non-linearity of model functions and non-optimal and lacking calibration sets deriving from sea truth collection difficulties often occur. This is mainly linked to the complexity of radiative light interactions involved, coupled with the expensiveness in terms of cost and resources needed for sampling and measurements in scuba diving activities.

In general, regression models, based on field measurements (independent variables, responses), are usually implemented through a well-established calibration and validation (CV) schema, in order to provide better predictive power. The calibration delivers the function model parameters by optimal fitting the responses of interest (i.e. LAI) using physically or statistically based functions models of independent variables (the spectral reflectance EO data) for a subset of the available measurements. In validation, the remaining measurements, different from those of calibration, provide a realistic predictive capability of the estimated model using independent data. In such a way, a more realistic evaluation of performance and expected errors may be available for the successive running of the calibrated model. In this framework, a sufficient number of measurements, likely greater than the few available at the station level, is required to apply such a scheme to suitably calibrate and validate models assessed, while also providing reliable insights into their robustness in terms of statistical significance and predictive power. In order to try to lower this negative impact linked to sea truth calibration incompleteness, we used both advanced machine learning algorithms, possibly robust against this unfavorable aspect, coupled with the partial expansion of the calibration data based on the radiometric variability in the area of the sampling stations, as explained in the following. For each station, the sea truth data of PO biophysical parameter variables was derived from in situ and laboratory measurement protocols as averages of plot systematic point sampling in a $50 \mathrm{x}$ $50 \mathrm{~m}$ area around the station center coordinates (Figure 4), while their resulting standard deviation was assumed as station measurement error. Therefore, an area of equivalent dimensions compatible with that seen by the S2 MSI satellite sensor, approximately equal to $5 \times 5$ pixels (window), centered on the single station, was used for the extraction of the corresponding point spectral signatures at pixel level. These different spectral signatures of the pixels crossing the areas of every measurement station were singularly used to suitably support the calibration/validation steps in the selected regression modelling approaches. In addition, considering the low number of stations sampled, a virtual station (station 0 ) was introduced in the vicinity of others where the bathymetry is incompatible with the presence of $\mathrm{PO}$, in order to better constrain the models.

Preliminarily, various S2 MSI frames, including the area of interest (AOI), were selected on the basis of cloud coverage and other noise (sun glint and current turbidity patterns) minimization. Then, the sea truth data with the corresponding spectral signatures extracted from station areas on the atmospherically pre-processed AOI images in the selected frames, were preliminarily tested using the MLRA approaches, available within the ENMAP toolbox running in the QGIS environment [30]. 
During the preliminary phase, in addition to the usual linear regression, the machine learning regression algorithms tested were: Gaussian Process regressor (GP), Kernel Ridge (KR), Linear Support Vector machine regressor (LSVR), Partial Least Square (PLS), Random Forest tree (RF), Support Vector Machine (SVR). Most of these approaches can provide effective and efficient solutions for regression and classification supervised tasks in EO data applications [29, 32, 33], using the preventive and effective transformation of the raw variables into higher dimensional representations of feature space, via different kernel functions, with the capability to suitably handle non-linearity of models with collinearity and other weaknesses in calibration/training data. The Support Vector Machine algorithms (LSVR, SVR) are based on the non-parametric supervised statistical learning technique, with robustness against outliers and limited training. They are able to estimate a hyperplane in the feature space that minimizes misclassifications. The RF consists of a group of decision trees induced by different sub-sets of the training data. Each tree in the forest casts a vote for the class with which a given analysis unit (in this case, a given segment) should be associated. The class with the most votes is the one associated with the segment [33]. Various statistical performance indicators were considered, starting from those of different error metrics coming from the difference between modelled/measured values under the form of Mean Error (ME), Mean Absolute Error (MAE), Root Mean Square Error (RMSE), Mean Square Error (MSE), Median Absolute Error (MedAE). In addition, others, linked to correlation between variables, such as Ratio of Performance to Deviation (RPD), Squared Pearson's $\left(\mathrm{r}^{2}\right)$, Explained variance score and Coefficient of determination $\left(\mathrm{R}^{2}\right)$ were also included. For the parameters of the first group based on different error metrics, minimization of their absolute values is required, while for others, linked to the correlation between calibration measurements, absolute maximum values are the best ones when superior to one for RPD and close to 1 for the absolute values of the others.

The supervised classification of the PO meadows and seabed covers in the coastal shallow waters of Lampedusa was implemented using the GP, LSVC, RF, and SVR MLCA, above introduced $[25,26]$. The training/validation set was obtained from point samples randomly extracted (stratified scheme) from various areas of the side scan sonar map, previously verified on available historical maps and georeferenced in order to guarantee its satisfying overlay with the PRISMA and S2 frames (RMS 1.5 pix). The relative performance of classifiers was evaluated via different accuracy metrics based on overall accuracy $(\mathrm{OA}), \mathrm{K}$-statistics $(\mathrm{k})$ and Mean-F1 accuracy parameters, derived from the related confusion matrices [26], with the best results linked to the maximization of values.

All the EO multi/hyperspectral data, extracted from images (previously selected by visual inspection of quick look) and subsequently corrected atmospherically using the available preprocessing options, was used for modeling through MLA in the regression and classification procedures. The selection of the best combination of frames, preprocessing option and MLA, in terms of global performance was accomplished based on results obtained in the validation step implemented through a 3-fold cross-validation method. This latter includes a random selection into three groups of the available sea truth data and related spectral signatures, and then one of them is used for calibration/training and the remaining two for validation/accuracy assessment. This step is repeated twice using the other two group combinations, and then the final values of the performance indicators are obtained as averages of the three partial outputs. Consequently, the final output choice was then performed, based on the performance parameters obtained in the modeling phase, for each frame and related atmospheric preprocessing option and specific MLA algorithm used. The thematic maps of the LAI-c and density continuous distributions of Pantelleria PO meadows and the seabed classes, including PO, of Lampedusa were produced using the best combination previously found.

The PO density distribution so obtained, coupled with the related bathymetry, allowed us to assess a four-class map of the health of PO meadows along the entire coast of Pantelleria island on the basis of the model first proposed by Pergent [38] and here 
suitably coded in the ERDAS-Imagine spatial modeler software environment. The model was developed several years ago with the support of an ample data set of sea truth observations and on the basis of the standard PO density distributions within a bathymetric range of 20 to $30 \mathrm{~m}$. It includes $4 \mathrm{PO}$ health classes, where the first two are disturbed meadows with a decreasing level of degradation and the last two healthy ones.

\section{Results}

The Tab. 1 includes LAI, shoot density (Den) and related cover (c) data, assessed from laboratory and in situ measurements collected on PO meadows during the 2015 and 2016 campaigns. The calculated uncertainties of each biophysical parameter were indicated in the right columns of the main values with the same label, starting with a capital $\mathrm{D}$. The cover values, produced by the on-purpose developed semiautomatic procedure using the digital underwater imagery of PO plots, were exploited to obtain refined values of the LAI (LAI-c). These refined values are lower compared to uncorrected ones and could be considered as the spatial density of LAI, $\left[\left(\mathrm{m}^{2} / \mathrm{m}^{2}\right)\right]$, more oriented to EO data calibration, than usual LAI evaluations at meadow level. In fact, they showed a better correlation with EO spectral reflectance responses of the reference area. The graph in Fig. 6, displays the corrected (using \% cover) and uncorrected LAI values, obtained from the data collected during the two sea truth campaigns.

Due to patchy and fragmented distributions, the LAI-c data is all lower than the corresponding uncorrected ones, while the values measured in 2016 are significantly less than those acquired in 2015 at the same station. The sea truth campaigns were carried out respectively in the early/middle of August 2015 and in late October 2016..

\begin{tabular}{|c|c|c|c|c|c|c|c|c|c|c|c|c|c|c|c|}
\hline \multirow[b]{2}{*}{ st. } & \multirow[b]{2}{*}{$\begin{array}{r}\text { Bath. } \\
\text { (m) }\end{array}$} & \multicolumn{7}{|c|}{2015} & \multicolumn{7}{|c|}{2016} \\
\hline & & $\begin{array}{c}\text { LAI } \\
\mathrm{m}^{2} / \mathrm{m}^{2}\end{array}$ & $\begin{array}{l}\text { DLAI } \\
\mathrm{m}^{2} / \mathrm{m}^{2}\end{array}$ & $\begin{array}{l}\text { Den. } \\
\mathrm{sh} / \mathrm{m}^{2}\end{array}$ & $\begin{array}{l}\text { Dden } \\
\mathrm{sh} / \mathrm{m}^{2}\end{array}$ & $\begin{array}{c}\text { Cov } \\
\%\end{array}$ & $\begin{array}{l}\text { LAI-c } \\
\mathrm{m}^{2} / \mathrm{m}^{2}\end{array}$ & $\begin{array}{l}\text { DLAI-c } \\
\mathrm{m}^{2} / \mathrm{m}^{2}\end{array}$ & $\begin{array}{c}\text { LAI } \\
\mathrm{m}^{2} / \mathrm{m}^{2}\end{array}$ & $\begin{array}{l}\text { DLAI } \\
\mathrm{m}^{2} / \mathrm{m}^{2}\end{array}$ & $\begin{array}{l}\text { Den. } \\
\mathrm{sh} / \mathrm{m}^{2}\end{array}$ & $\begin{array}{l}\text { Dden } \\
\mathrm{sh} / \mathrm{m}^{2}\end{array}$ & $\begin{array}{c}\text { Cov } \\
\%\end{array}$ & $\begin{array}{l}\text { LAI-c } \\
\mathrm{m}^{2} / \mathrm{m}^{2}\end{array}$ & $\begin{array}{l}\text { DLAI-c } \\
\mathrm{m}^{2} / \mathrm{m}^{2}\end{array}$ \\
\hline 1 & 10 & 3,37 & 0,86 & 112,80 & 37,48 & 69,20 & 2,33 & 0,59 & 1,57 & 0,51 & 61,60 & 10,807 & 43,65 & 0,69 & 0,22 \\
\hline 2 & 20 & 2,19 & 0,73 & 139,20 & 10,33 & 65,70 & 1,44 & 0,48 & 1,13 & 0,36 & 65,60 & 19,308 & 47,15 & 0,53 & 0,17 \\
\hline 4 & 30 & & & & & & & & 1,83 & 0,40 & 54,40 & 17,573 & 23,15 & 0,42 & 0,09 \\
\hline 3 & 31 & 2,62 & 1,21 & 121,60 & 33,57 & 48,90 & 1,28 & 0,59 & 1,05 & 0,51 & 80,80 & 15,849 & 33,80 & 0,35 & 0,17 \\
\hline
\end{tabular}

Table 1- Biophysical parameters estimates derived from sea truth data collected in the 2015 and 2016 campaigns, and laboratory biometric measurements for all the stations. The station n. 4 was introduced in 2016

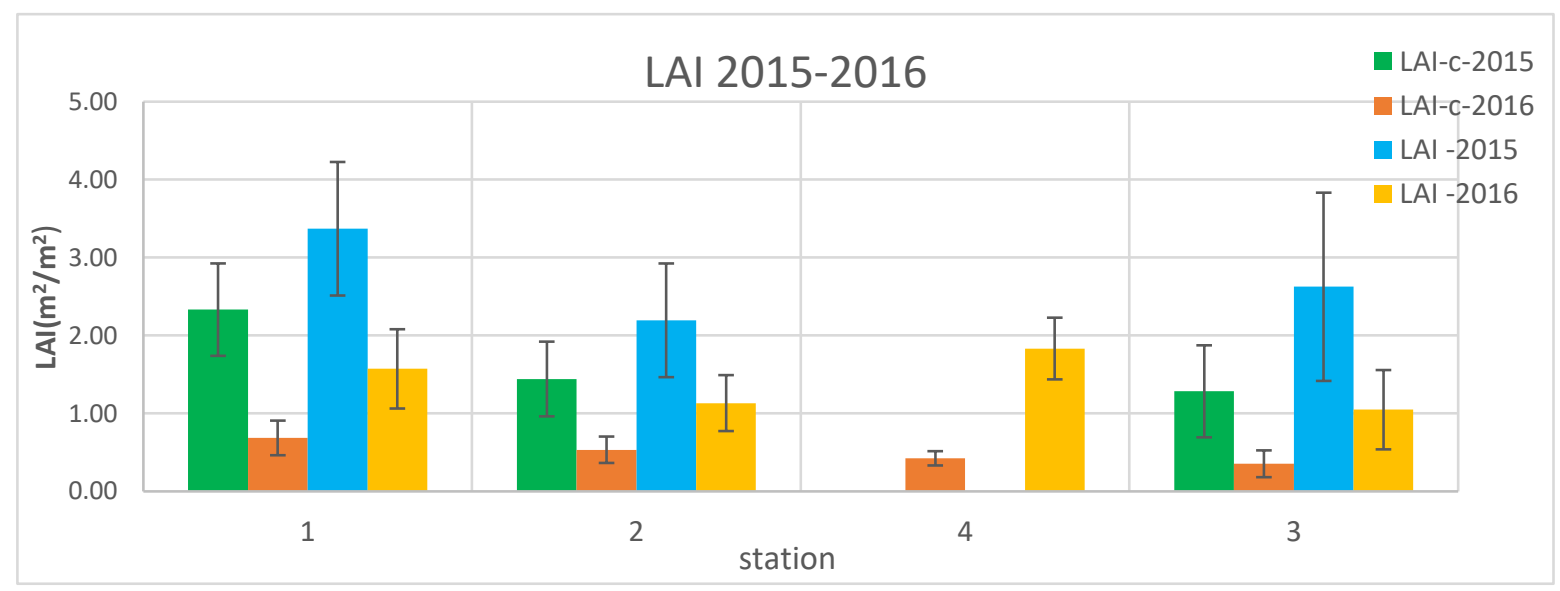

Figure 6- LAI assessment with LAI-c related values, corrected using cover estimates provided by the semiautomatic segmentation procedure, for the 2015 and 2016 sea truth campaigns. The station values were reported according their growing bathymetry. 
At the beginning of autumn, the PO, like terrestrial photosynthetic plants, loses both the old leaves and the ends of the younger ones damaged by the first storms, which we find on the beaches as biodegradable waste material. Therefore, the decrease in LAI and biomass observed in the measurements relating to the two campaigns may likely be due to the different seasonal vegetative stage linked to the dates on which they were conducted. According to the light attenuation with bathymetry, the LAI parameters both decrease as depth increases from sampling station 1 to 4 (Fig. 5).The PO density trend (Fig. 7), doesn't show an inverse dependence on the bathymetry, but it evidences the decreases linked to the different seasonal stage of PO plants in the two campaigns.

\begin{tabular}{|c|c|c|c|c|c|c|c|c|c|}
\hline & \multirow[b]{2}{*}{ Bath. } & \multicolumn{4}{|c|}{2015} & \multicolumn{4}{|c|}{2016} \\
\hline & & $\begin{array}{c}\text { Bio } \\
\text { (F.W.) }\end{array}$ & $\begin{array}{l}\text { DBio } \\
\text { (F.W) }\end{array}$ & $\begin{array}{c}\text { Biod } \\
\text { (D.W.) }\end{array}$ & $\begin{array}{l}\text { DBiod } \\
\text { (F.W) }\end{array}$ & $\begin{array}{c}\text { Bio } \\
\text { (F.W.) }\end{array}$ & $\begin{array}{c}\text { DBio } \\
\text { (F.W) }\end{array}$ & $\begin{array}{l}\text { Biod } \\
\text { (D.W.) }\end{array}$ & $\begin{array}{l}\text { DBiod } \\
\text { (F.W) }\end{array}$ \\
\hline st. & (m) & $\mathrm{g} / \mathrm{sh}$ & $\mathrm{g} / \mathrm{sh}$ & $\mathrm{g} / \mathrm{sh}$ & $\mathrm{g} / \mathrm{sh}$ & $\mathrm{g} / \mathrm{sh}$ & $\mathrm{g} / \mathrm{sh}$ & $\mathrm{g} / \mathrm{sh}$ & $\mathrm{g} / \mathrm{sh}$ \\
\hline 1 & 10 & 8,190 & 1,644 & 1,280 & 0,198 & 3,383 & 2,316 & 0,675 & 0,359 \\
\hline 2 & 20 & 4,840 & 1,800 & 0,900 & 0,248 & 4,099 & 2,450 & 0,863 & 0,398 \\
\hline 4 & 30 & & & & & 4,307 & 2,732 & 0,804 & 0,387 \\
\hline 3 & 31 & 7,37 & 1,88 & 1,24 & 0,29 & 6,267 & 2,386 & 1,005 & 0,396 \\
\hline
\end{tabular}

Table 2- Biomass estimates as fresh and dry specific weights( per shoot, derived from samples data collected in the 2015 and 2016 sea truth campaigns, and laboratory biometric measurements for all the stations. The station n. 4 was introduced in 2016.

The measured biomass shows a decrease in the middle stations in 2015, while in 2016 the measurements consistently rise with the bathymetry, but both with the related uncertainties that reduce their reliability (tab. 2).

On the EO data side, the visual selection of the potentially exploitable imagery was carried out by discharging those affected by clouds over the interest area and water turbidity patterns from sea currents on the water surfaces to be monitored. The removal of atmospheric noise (mainly from aerosol variable distribution over the water surfaces of interest) from the multispectral frames acquired by the S2 MSI sensor was first accomplished through the above mentioned ACOLITE operational tool. The S2 multispectral images for Pantelleria were acquired on 30-08-2015 and 21-11-2016, based on the previously described criteria, including regression performance parameters metric obtained for the various MLCA (see fig. 9, table 3). Similarly, the frames of PRISMA and S2 sensors exploited for the Lampedusa MLCA application were indicated in table 3.

Fig. 8 shows the results of the ACOLITE DSF modelling for the S2 frames acquired on 30-08-2015 (a) and 14-08-2016 (b), while Fig. 9 displays the results of atmospheric
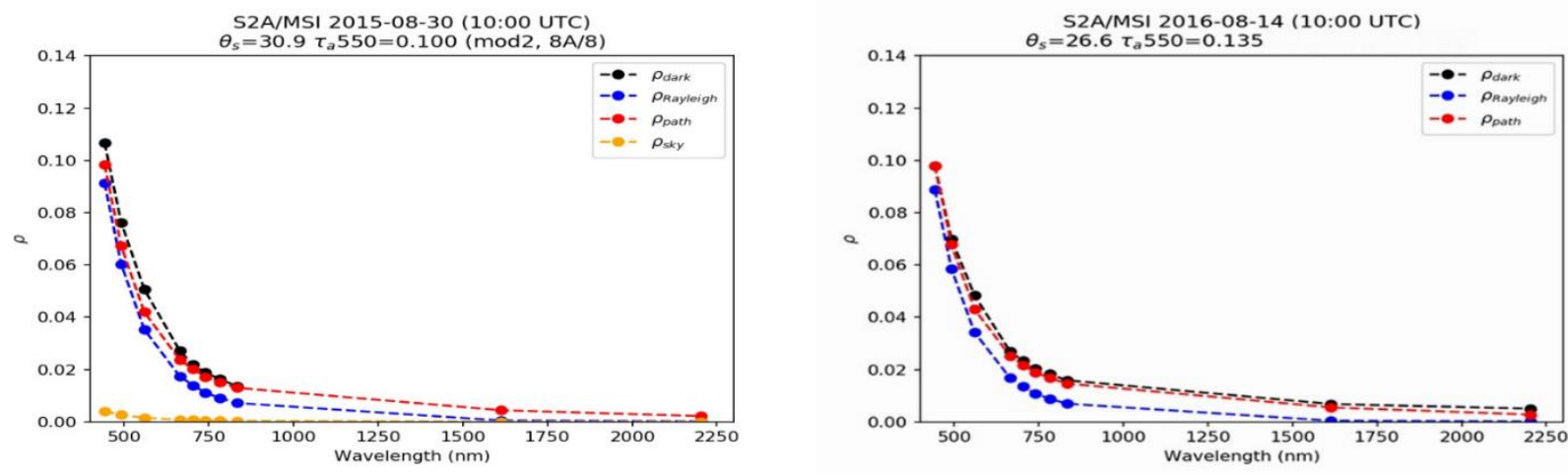

(a) Figure 8 - ACOLITE Dark Spectrum modelling Fit (b)SF) for the S2 MSI multispectral images acquired on 30-08-2015 (a) and 14-08-2016 (b). The sensor zenithal angle and AOD retrieved at $550 \mathrm{~nm}$ were also reported. 
correction steps performed using the different tools/options available, including those provided by the ICOR code for adjacency effects removal.

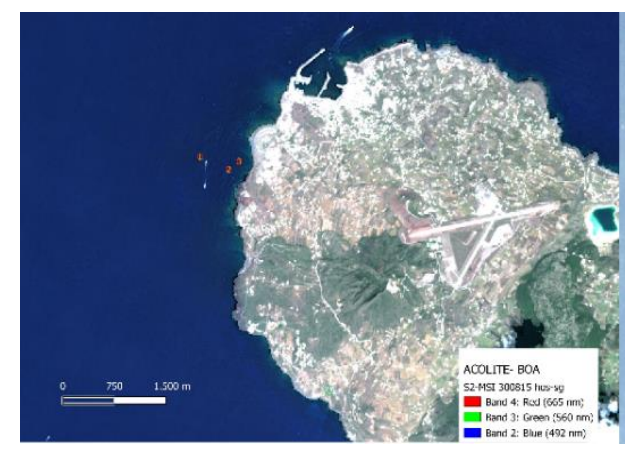

(a)

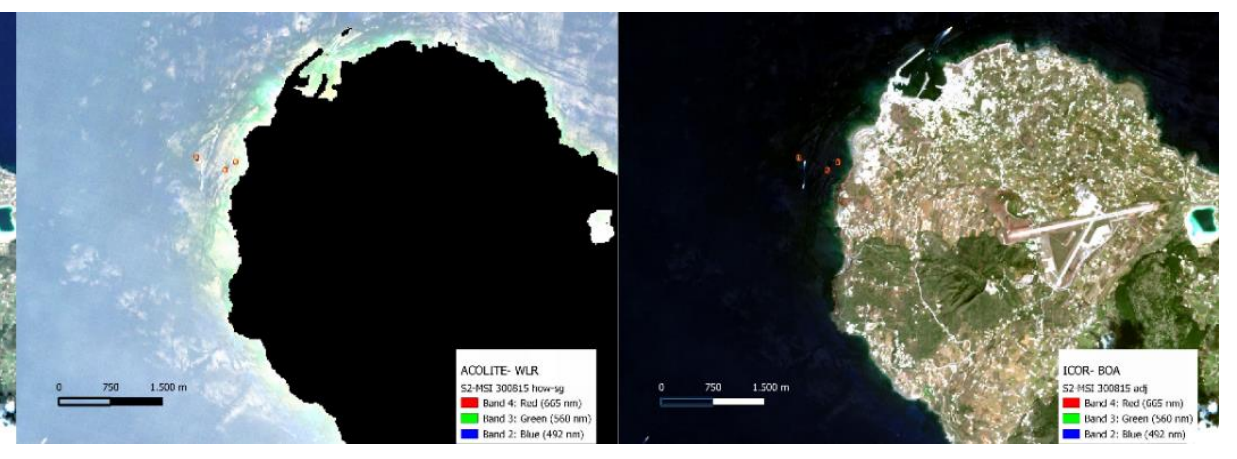

(b)

(c)

Figure 9 - Results from the different atmospheric corrections applied to the S2 MSI TOA multispectral data of Pantelleria island: ACOLITE BOA (Bottom of Atmosphere) system corrected (a); ACOLITE WLR (Water leaving Radiance/reflectance) (b); ICOR BOA radiance/reflectance (c).

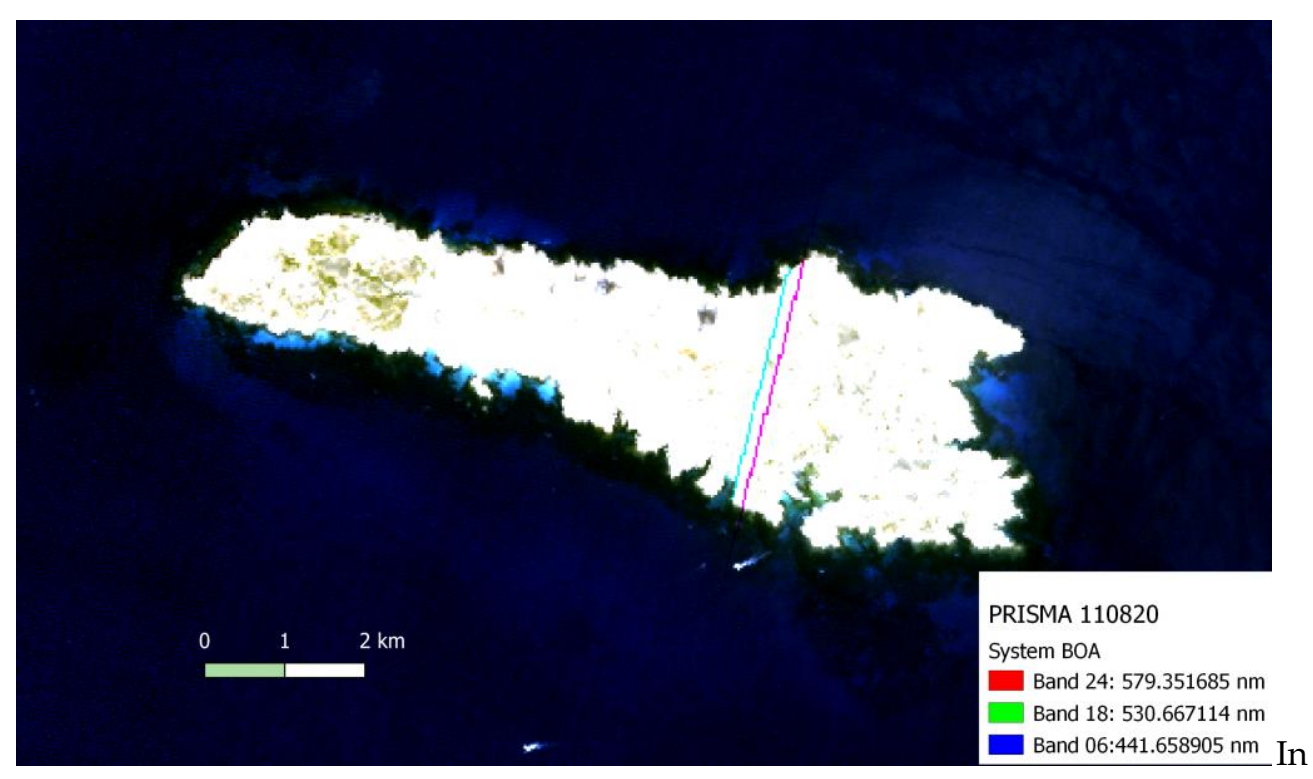

Fig. 5, a combination of system corrected (BOA) PRISMA VIS channels is displayed as the background of the distribution of seabed training classes derived from the s. s. sonar map. In Fig. 10, a different false color image of atmospherically corrected (BOA) hyper-spectral PRISMA components, in the blue-green range, is reported. Given the high water penetration of the blue-green light made exploitable through the various PRISMA bands, many costal seabed features can be better

Figure 10 - Atmospherically corrected (BOA) PRISMA hyperspectral image of Lampedusa, acquired on 11-08-2020. Some sensor artifacts as colored lines cross the right part of the image.

identified as the bluish areas on the left-lower coast of the island, corresponding to thin sand cover.

The point-pixel spectral signatures, extracted from the atmospherically preprocessed images of the areas of sampling stations of Pantelleria, were coupled with the related LAIc values in order to assess the regression models using the different MLRA algorithms. The graphs in figure 11 show the regression models assessed from the 30-08-2015 and 22- 
11-2016 S2 WLR distributions provided by the ACOLITE code. The best models were estimated using the KR and LSVR MLRA.

In the graphs, each dot represents a different pixel-point spectral signature extracted
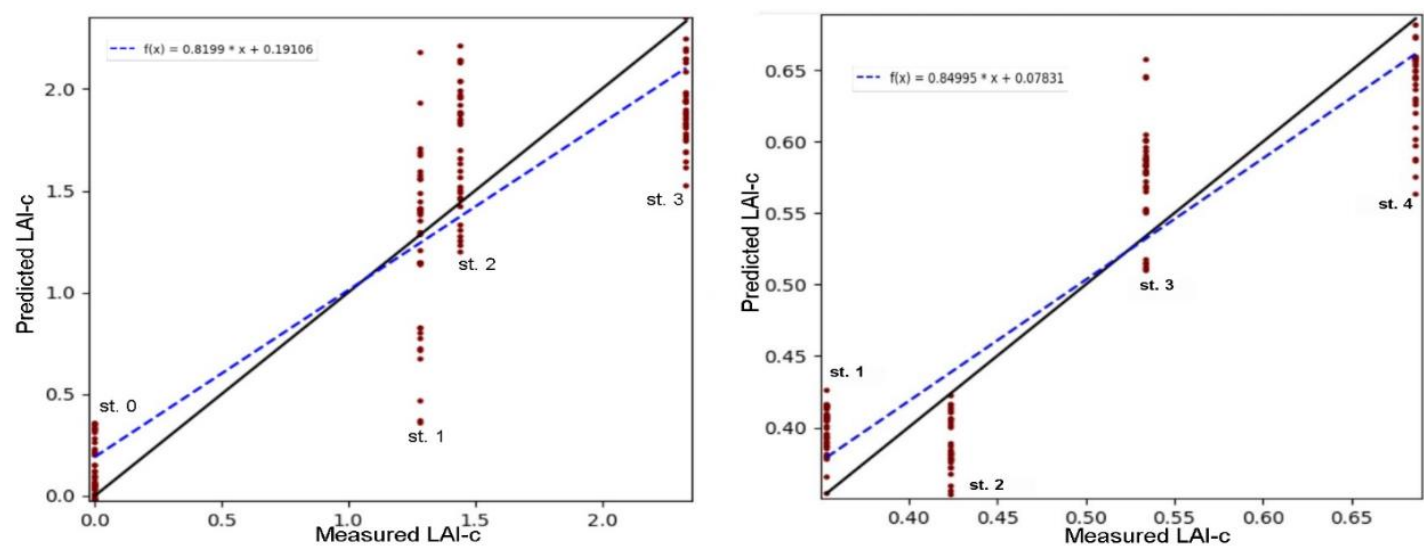

from the preprocessed multispectral data of the corresponding sampling station areas.

The station 0 (st. 0), with the corresponding null value for LAI-c, in the left graph corresponds to bathymetry of $40 \mathrm{~m}$ and consequent $\mathrm{PO}$ absence.

Table 3 includes the list of the best combinations found at the level of S2 frames, preprocessing options, and MLRA, with the related performance parameters for the models of PO LAI-c distribution on the Pantelleria coasts for the 2015 and 2016 years. The ATM column of Tab. 3 embraces different radiometric preprocessing options. In particular, $\mathrm{ACO}$ + the suffixes HW and HS refer respectively to WLR and BOA (with sun glint removal and without adjacency correction), while ICOR indicates BOA with adjacency correction and without sun glint removal.

\begin{tabular}{|c|c|c|c|c|c|c|c|}
\hline (a) Date & ATM & MAE & RMSE & MSE & $r^{2}$ & $\mathbf{R}^{2}$ & MLRA \\
\hline \multirow{2}{*}{$\begin{array}{l}\text { 30/08/zo15 } \\
\text { วn/no /วn15 }\end{array}$} & ACO-HW & 0.2912 & 0.3702 & $0.137(\mathrm{~b})$ & 0.8173 & 0.8168 & $\mathrm{KR}$ \\
\hline & Irnd & ก วกon & ח & ก 2กก1 & $n$ 75[? & n & RF \\
\hline \multirow{2}{*}{\multicolumn{7}{|c|}{$\begin{array}{l}\text { Figure } 11 \text { - LAI-c models estimated from the 30-08-2015 (a) and 22-11-2016 (b) S2 } \\
\text { preprocessed (WLR) frames, using respectively KR and LSVR MLRA algorithms }\end{array}$}} & RF \\
\hline & & & & & & & SVR \\
\hline 08/12/2015 & ACO-HW & 0.3765 & 0.4588 & 0.2105 & 0.7449 & 0.7156 & $\mathrm{KR}$ \\
\hline $22 / 11 / 2016$ & ACO-HW & 0.0436 & 0.0495 & 0.0024 & 0.8438 & 0.8431 & LSVR \\
\hline $14 / 08 / 2016$ & ACO-HS & 0.1028 & 0.1217 & 0.0148 & 0.7182 & 0.7147 & PLS \\
\hline
\end{tabular}

Table 3 - Best combinations found for regression models of PO LAI-c distribution of Pantelleria coast, using preprocessed S2 frames and sea truth data of 2015 and 2016 with different MLRA

A subset of values obtained for the most relevant regression performance parameters were also reported with the indication of the exploited MLRA. The best results for the years 2015 and 2016 were obtained using the frames of 30/08 and 22/11, preprocessed with ACOLITE for WLR retrieval. For these frames, the regression models with the highest performance were those provided by KR and LSVR MLRA, with $\mathrm{R}^{2}$ values of 0.81 and 0.84 . The inferior results for both years, in terms of error and correlation performance parameters, of the BOA distribution provided by ACOLITE and ICOR, preliminarily suggest that the WLR retrieved by ACOLITE is the most effective atmospheric preprocessing method to allow seagrass mapping. The most effective MLRA with the 2015 frames following the KR were SVR and RF, while for 2016 the best are LSVR and PLS. The differences between the ranges of absolute values of calibration measurements acquired in the 
two campaigns and the internal variation within each dataset may involve the diverse capacity of a specific MLRA to better model the required trends.

As stressed before, due to different campaign dates, the 2015 LAI calibration values are significantly higher than the related values measured in 2016, with less discriminability of measurement stations and consequently different MLRA effectiveness in distribution modelling. In any case, the regression global performance, in terms of both error and correlation parameters, achieved the best result using the preprocessed frame of 22-112016 with the LSVR model, followed by that of 2015 provided by the KR MLRA (Tab. 3). The local distributions, assessed using the best 215 and 2016 models, are reported in Fig. 12. Their PO patch distributions were also in satisfactory accordance with the preexisting information and maps available, even though they were not updated (i.e. M.A.T.T.M.SiDiMar. GIS-Geodatabase, 2008). Since the latter are mainly based on observations of the summer period, the agreement of the 2016 autumn distribution (more affected by thin cloud presence at the upper corner of the area of interest) is less strong. Furthermore, from a qualitative comparison with this auxiliary GIS information (SidiMar), it happens that the model estimated for PO distribution in 2015 through the KR MLRA is less stable spatially at global level and less effective for the correct mapping of the PO of the entire island than that derived from the RF (Tab. 3, fig. 13), although the latter is less performant with sea truth point data.

Due to different seasonal development periods of $\mathrm{PO}$ in the sea truth campaign dates, a direct comparison between the LAI-c distributions is useless for assessing the potential impact of the ISWEC prototype, but in any case, the LAI-c map of 2016 doesn't show a

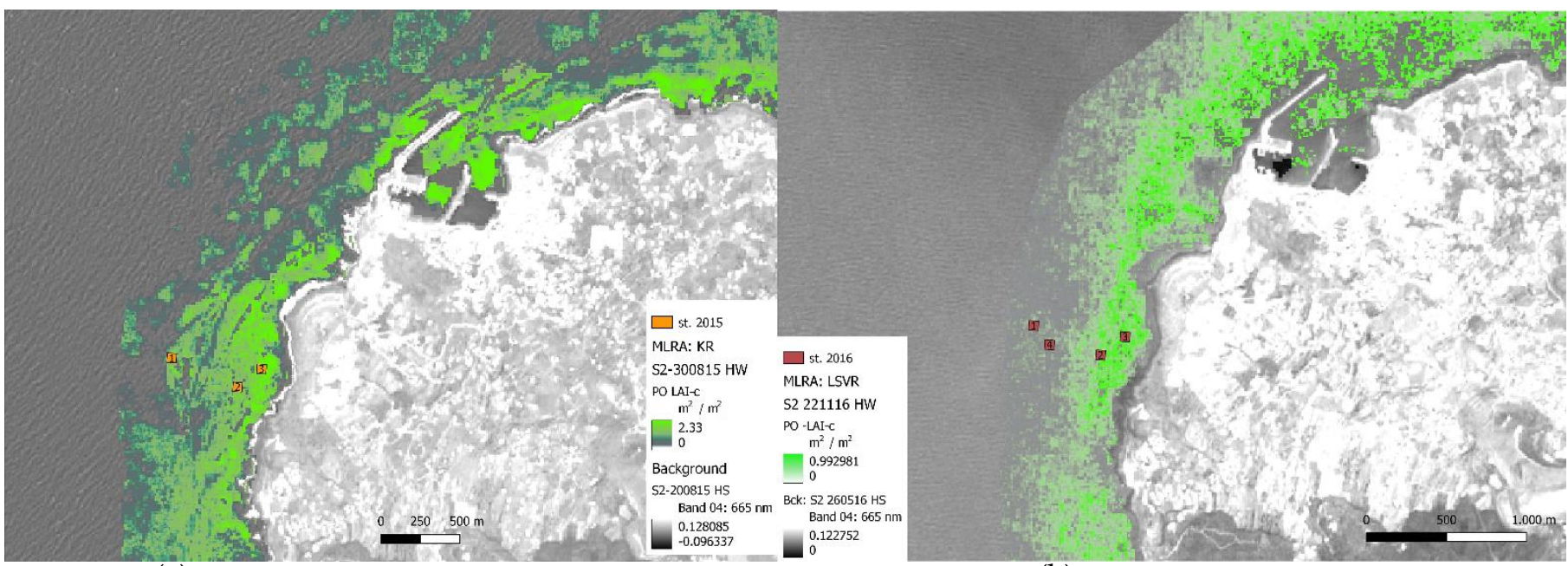

(a)

significant discontinuity and reduction in the proxirftity of the converter plant. This suggests that the installation of the prototype, thanks to its technical solution to minimize the

Figure 12 - PO LAI-c distribution assessed from the S2 WLR preprocessed images using different MLRA calibrated by means of 2015 (a) and 2016 (b) sea truth data. Some values in the upper left corner of the of the 2016 map were masked out due to the presence of thin clouds.

the seabed beneath (i.e., floating mooring), did not significantly impact the nearby PO meadows.

The PO density (shoots $/ \mathrm{m}^{2}$ ) distribution was assessed using the WLR derived from the 30-08-2015 S2 frame through SVR, which has been found to be the most performant MLRA, although with poor parameter values $\left(\mathrm{r}^{2}=0.401, \mathrm{R}^{2}=0.316\right)$. The $\mathrm{PO}$ health map based on the Pergent model, obtained from these EO derived density and bathymetry distributions, is shown in Fig. 14. In general, from the health map you can see that most of the PO meadows on the Pantelleria coast are in equilibrium with normal or high density and there aren't areas of abnormal density, with highly disturbed meadows. Small areas 
of stressed PO (disturbed - low dens.) meadows were detected in proximity to the harbor, probably linked to the concentration of anthropogenic activities and ship traffic.

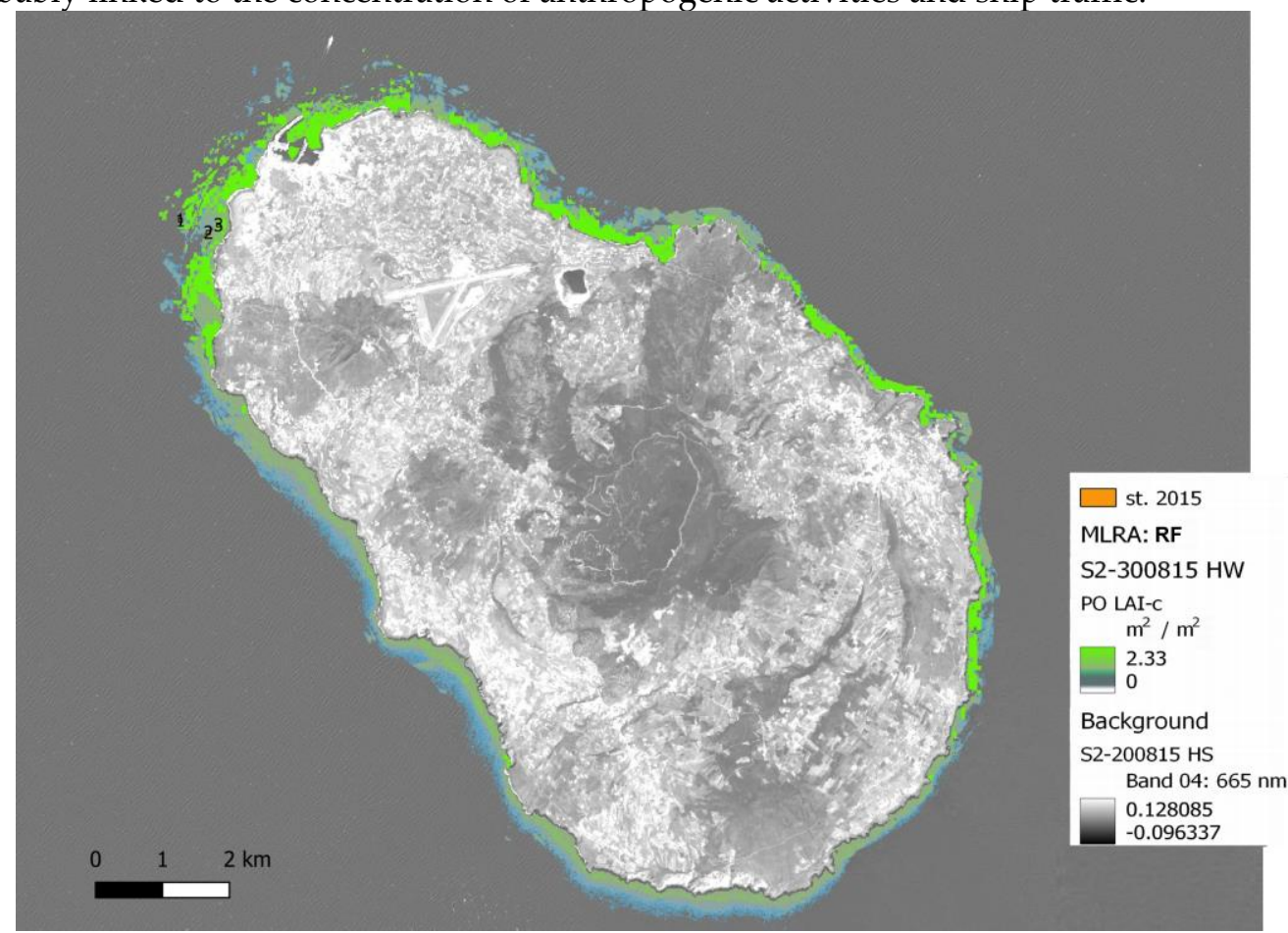

Figure 13 - LAI-c distribution assessed for the entire coast of Pantelleria island using RF MLRA.

Tab. 4 includes the performance parameters evaluated for classification maps obtained through different MLCA using the BOA hyperspectral data of Lampedusa, acquired by the PRISMA sensor on 11-08-2020. The results obtained through SVC and LSVC were the two best (evaluated O.A. respectively, 82.64 and 78.46) while those related to RF and GP ranked correspondingly at intermediate and worst levels.

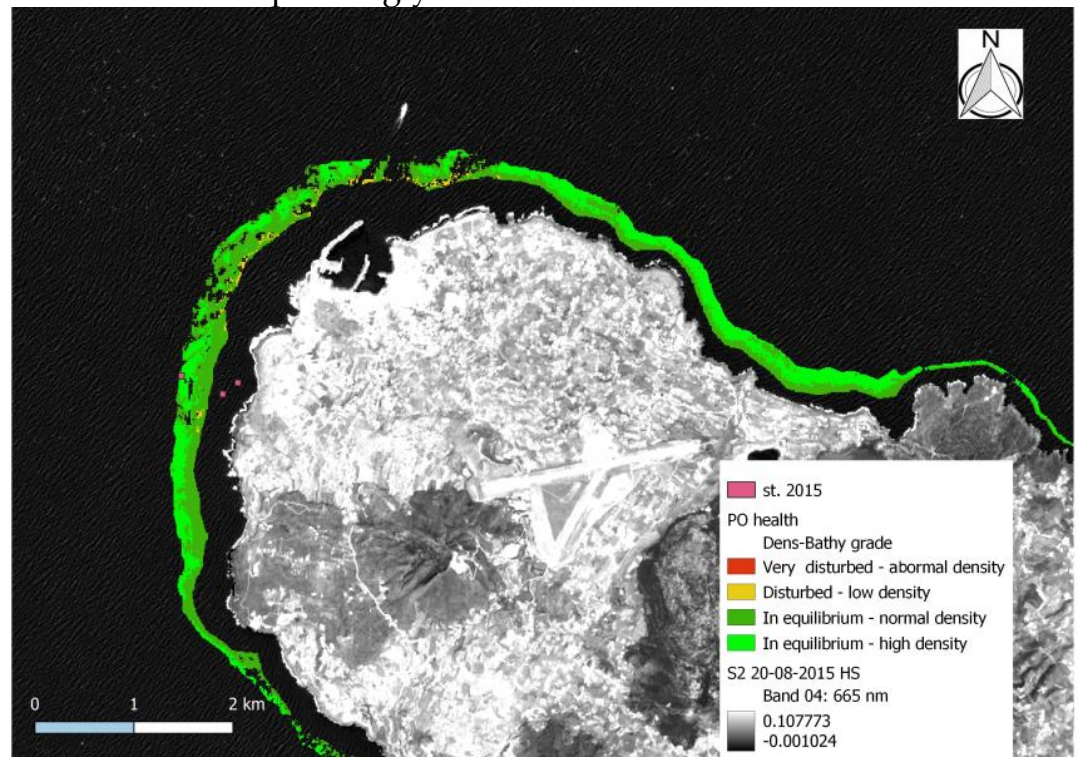

Figure 14 - Four density derived classes of PO health within 20-30 m bathymetry range, according to Pergent model. 
The Tab. 5, in addition to listing the best of these accuracy parameters for classification of PRISMA hyperspectral data, also shows those evaluated for thematic maps from S2 MSI multispectral data, obtained through the different radiometric preprocessing options (BOA and WLR water-oriented atmospheric with sun-glint and adjacency effects removal) under the ATM column. Here the accuracy metric shows that, in general, the water oriented ACOLITE pre-processing (prefix ACO) performs better than that of ICOR (BOA and adjacency effect re-moval). Moreover, the ACOLITE BOA, including sun-glint (ACO-HS), is less effective than WLR ACOLITE (ACO-HW).

Table 4 Accuracy assessment parameters estimated for seabed and PO thematic maps obtained by supervised classification of PRISMA (BOA) data through different MLCA

The following figures display the thematic maps obtained using the SVC MLCA, with data from PRISMA hyperspectral BOA VIS (Fig. 15) and from S2 multispectral WLR

\begin{tabular}{|c|c|c|c|c|c|c|c|c|c|c|c|c|}
\hline \multirow{3}{*}{$\begin{array}{l}\text { param- } \\
\text { eter } \\
\text { Overall }\end{array}$} & \multicolumn{12}{|c|}{ MLCA } \\
\hline & \multicolumn{3}{|c|}{ GPC } & \multicolumn{3}{|c|}{ LSVC } & \multicolumn{3}{|c|}{$\mathbf{R F}$} & \multicolumn{3}{|c|}{ SVC } \\
\hline & $\begin{array}{c}\text { Esti- } \\
\text { mate } \\
{[\%]}\end{array}$ & \multicolumn{2}{|c|}{$\begin{array}{c}95 \% \text { Confi- } \\
\text { dence Interval } \\
{[\%]}\end{array}$} & $\begin{array}{c}\text { Esti- } \\
\text { mate } \\
{[\%]}\end{array}$ & \multicolumn{2}{|c|}{$\begin{array}{c}95 \% \text { Confi- } \\
\text { dence Interval } \\
{[\%]}\end{array}$} & $\begin{array}{c}\text { Esti- } \\
\text { mate } \\
{[\%]}\end{array}$ & \multicolumn{2}{|c|}{$\begin{array}{c}95 \% \text { Confi- } \\
\text { dence Interval } \\
{[\%]}\end{array}$} & $\begin{array}{c}\text { Esti- } \\
\text { mate } \\
{[\%]}\end{array}$ & \multicolumn{2}{|c|}{$\begin{array}{c}95 \% \text { Confi- } \\
\text { dence Interval } \\
{[\%]}\end{array}$} \\
\hline $\begin{array}{r}\text { Accu- } \\
\text { racy }\end{array}$ & 24.76 & 22.0 & 27.44 & 78.46 & 74.0 & 82.83 & 76.53 & 72.0 & 80.97 & 82.64 & 79.0 & 86.54 \\
\hline \multicolumn{13}{|l|}{ Карра } \\
\hline $\begin{array}{r}\text { Accu- } \\
\text { racy }\end{array}$ & 7.44 & -3.0 & 17.88 & 74.02 & 68.51 & 79.53 & 71.71 & 66.02 & 77.4 & 79.09 & 74.03 & 84.14 \\
\hline Mean & & & & & & & & & & & & \\
\hline $\begin{array}{l}\text { F1 Ac- } \\
\text { curacy }\end{array}$ & 13.76 & - & & 79.21 & - & & 77.78 & - & & 83.39 & - & \\
\hline
\end{tabular}

(Fig. 16), acquired on the dates indicated (Tab. 5).

\begin{tabular}{|c|c|c|c|c|c|c|c|c|c|c|}
\hline \multirow{2}{*}{ Date } & \multirow{2}{*}{ sensor } & \multirow[t]{2}{*}{ ATM } & \multirow[t]{2}{*}{$\begin{array}{l}\text { Overall } \\
\text { Accuracy } \\
\text { (OA) }\end{array}$} & \multicolumn{2}{|c|}{$\begin{array}{l}\text { OA 95\% confi- } \\
\text { dence inter- } \\
\text { vals(\%) }\end{array}$} & \multirow[t]{2}{*}{$\begin{array}{l}\text { Kappa Ac- } \\
\text { curacy (K) }\end{array}$} & \multicolumn{2}{|c|}{$\begin{array}{l}\text { К 95\% confi- } \\
\text { dence inter- } \\
\text { vals(\%) .. }\end{array}$} & \multirow[t]{2}{*}{$\begin{array}{l}\text { Mean F1 } \\
\text { Accuracy }\end{array}$} & \multirow[t]{2}{*}{ MLCA } \\
\hline & & & & & & & & & & \\
\hline 21/08/2016 & S2 & ACO-HW & 82.22 & 78.0 & 86.01 & 78.67 & 73.94 & 83.4 & 82.32 & SVC \\
\hline 21/08/2016 & S2 & ACO-HW & 78.33 & 74.0 & 82.28 & 74.0 & 68.92 & 79.08 & 77.86 & $\mathrm{RF}$ \\
\hline $21 / 08 / 2016$ & S2 & ACO-HS & 80.56 & 77.0 & 84.47 & 76.67 & 71.77 & 81.56 & 80.56 & SVC \\
\hline 21/08/2016 & S2 & ACO-HS & 79.17 & 75.0 & 83.1 & 75.0 & 69.99 & 80.01 & 78.88 & $\mathrm{RF}$ \\
\hline $11 / 08 / 2020$ & PRISMA & $\mathrm{BOA}$ & 82.64 & 79.0 & 86.54 & 79.09 & 74.03 & 84.14 & 83.39 & SVC \\
\hline $11 / 08 / 2020$ & PRISMA & $\mathrm{BOA}$ & 78.46 & 74.0 & 82.83 & 74.02 & 68.51 & 79.53 & 79.21 & LSVC \\
\hline $21 / 08 / 2016$ & S2 & ICOR & 77.78 & 74.0 & 81.73 & 73.33 & 68.21 & 78.46 & 77.08 & SVC \\
\hline $21 / 08 / 2016$ & S2 & ICOR & 76.67 & 73.0 & 80.71 & 72.0 & 66.77 & 77.23 & 76.34 & $\mathrm{RF}$ \\
\hline
\end{tabular}

MLCA

Table 5 Accuracy assessment parameters metric estimated for seabed and PO thematic maps obtained by supervised classification of S2 and PRISMA EO data obtained from various preprocessing options (ATM column) by means of different MLCA.

The retrieved seabed class distribution, in addition to the high accuracy metric referring to sea truth (side-scan sonar map), shows a good deal with each other and with historical data (SiDi MAR). As regards the PO meadows distribution. As regards the 
distribution of other seabed classes, there is a slight difference in the percentage of rock coastal areas compared to those with fine sand in the two thematic EO derived products. The PRISMA thematic product shows a better capacity to detect rocks and intermediatecoarse sand areas and a poorer $\mathrm{PO}$ patch geometric characterization, probably due to its geometric resolution $(30 \mathrm{~m})$, lower than that of $\mathrm{S} 2(10 \mathrm{~m})$.

In both PRISMA and S2 thematic maps, the PO areas are in agreement with test data (side scan sonar) but happen overestimated respect to the older distribution (SidiMar), with a different detection of the coarse sand dunes area in the southern part of the island. Ultimately, although the PRISMA sensor with its multiple narrow bands in the visible with basic atmospheric preprocessing has demonstrated the best thematic accuracy metric $(\mathrm{O} . \mathrm{A} .=82.64)$, the results of the $\mathrm{S} 2$ sensor, suitably preprocessed using water surface options, are slightly lower (O.A.=82.22), with a difference of less than $5 \%$.

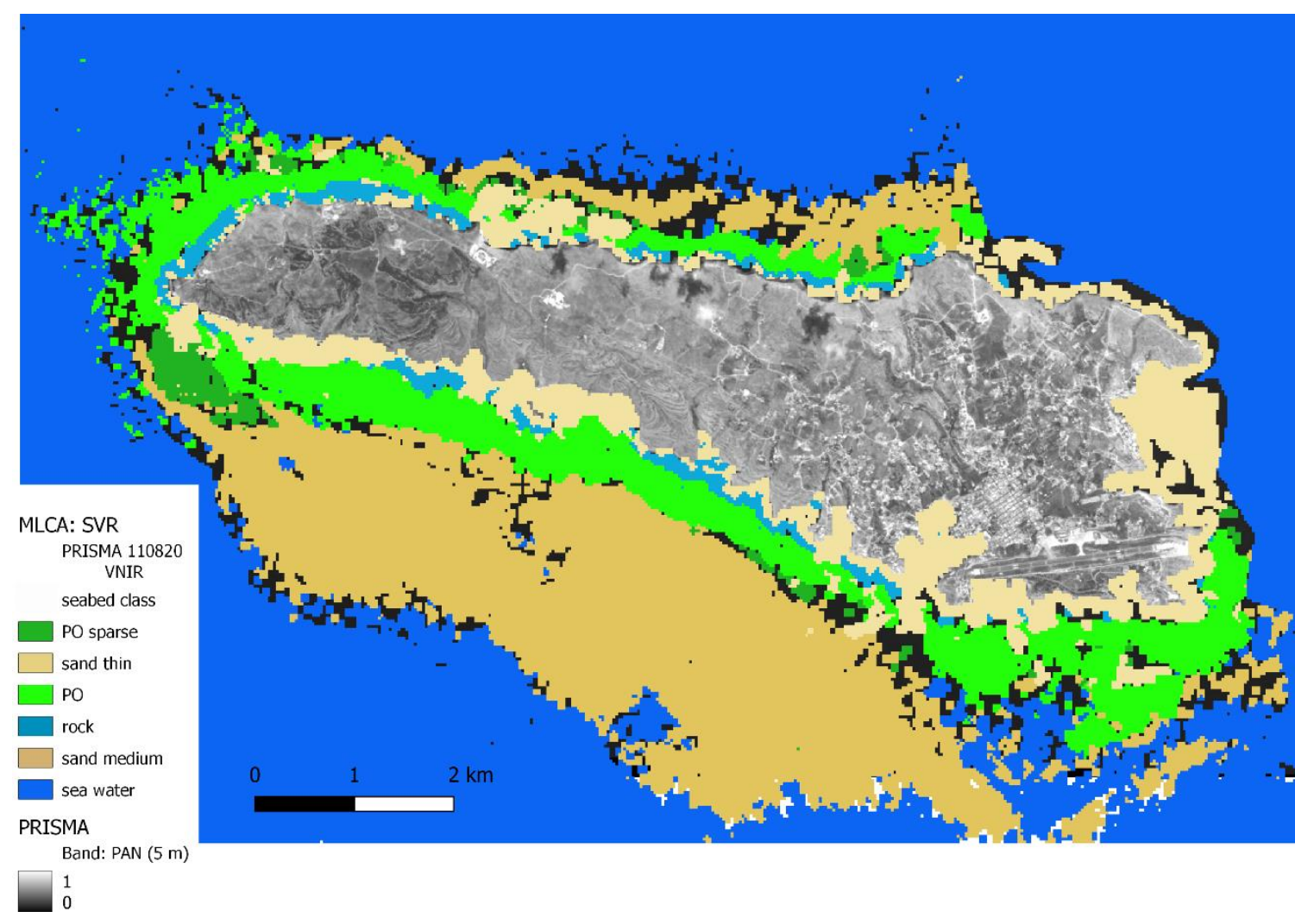

Figure 15 - PO and seabed distribution classes assessed through SVR MLCA using PRISMA BOA hyperspectral data. The PRISMA panchromatic channel is used for the land island area while the black region indicate the unclassified ( confidence level $<80 \%$ ). 


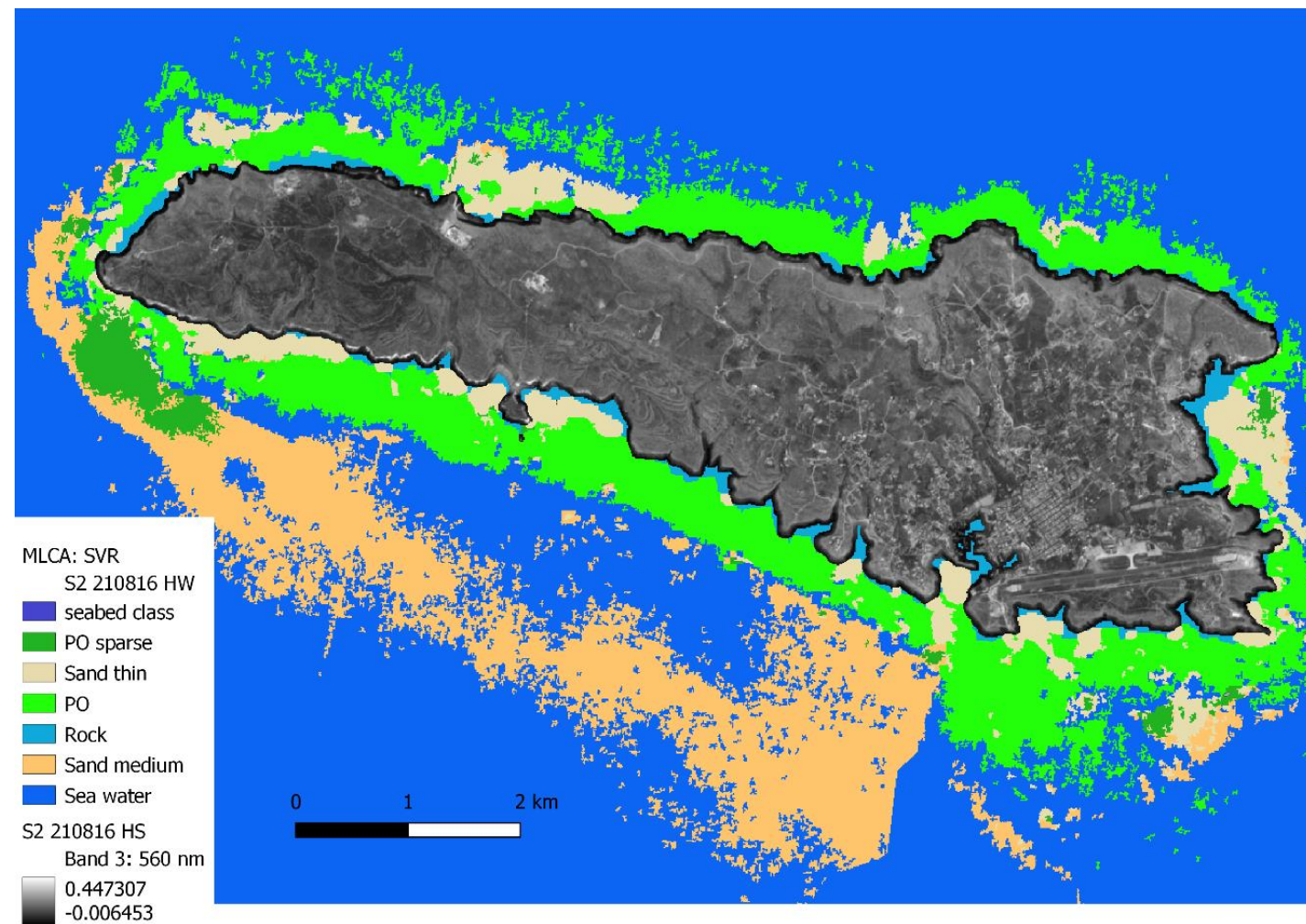

Figure 16 PO and seabed distribution classes assessed through SVR MLCA using S2 WLR multispectral data. The S2 BOA green band $(560 \mathrm{~nm})$, is used for the land island area.

\section{Conclusion}

The PO meadows and sea beds of Pantelleria and Lampedusa islands were serviceably monitored and mapped through the developed methodology based on the EO data provided by the last generation of the S2 MSI and PRISMA multi/hyperspectral HR sensors, with their ampler selection of suitable frames and acquisition channels coupled with effective radiometric preprocessing for removing the different atmospheric noises from captured frames. Various approaches for coastal atmospheric pre-processing of EO data were integrated with different machine learning algorithms to properly support the regression/classification advanced modelling, calibrated/validated through sea truth data, collected and processed by means of original methods.

The distribution of density and LAI of PO meadows of the Pantelleria coast were estimated through S2 EO data, focusing on the location of the ISWEC energy converter prototype on the north-east coast, where the sea truth calibration data was collected in 2015 and 2016. The LAI $\left(\mathrm{m}^{2} / \mathrm{m}^{2}\right)$ and density $\left(\right.$ shoots $\left./ \mathrm{m}^{2}\right)$ distributions of PO meadows were effectively assessed by means of preprocessed EO multispectral data using the most performant MLRAs ( $\mathrm{R} 2=0.81, \mathrm{R} 2=0.84$ ). In this context, the $\mathrm{S} 2 \mathrm{WLR}$ data, atmospherically corrected using the advanced ACOLITE package, have been found to be the most effective for monitoring and modelling the $\mathrm{PO}$ and seagrass biophysical parameters distributions.

The PO health distribution map, derived from estimated density according to the Pergent model, highlighted the satisfactory meadows condition in the vicinity of the ISWEC and throughout the island, except in small areas near the harbor, likely more subjected to anthropogenic impacts.

The preprocessed S2 and PRISMA EO data were successfully exploited for mapping the seabed and PO of Lampedusa shallow waters using different MLA classification approaches based on supervised schemes. The accuracy metric of the classification map obtained from the PRISMA hyperspectral data (BOA atmospherically corrected without sun glint and adjacency effects removal) was the best. The results, in terms of the accuracy metric of the classification based on S2 WLR data and the most performant MLCA, were 
a bit lower $(\mathrm{OA}=82.22)$, while the others corresponding to different processing options follow.

The results above described may provide a preliminary indication of the suitability of the last generation multispectral S2 MSI and hyperspectral PRISMA sensors for coastal ecosystems and shallow water monitoring, specifically for PO mapping purposes, strongly dependent on the radiometric pre-processing procedure for atmospheric noise removal. The integration of atmospheric preprocessing packages for EO HR multi/hyperspectral data to couple the WLR retrieval with the removal of the sun glint and adjacency effects is required, also for the ongoing hyperspectral missions (i.e. ENMAP), in the perspective of further improvement of the developed methodology. The results achieved demonstrate that the integrated use of these recent satellite HR remote sensing multi/hyperspectral techniques through advanced MLA, even supported by limited on-site surveys, represents an effective and extensive mapping tool for supporting the sustainable management of island coastal environments and PO habitats in shallow waters. This is also guaranteed in the case of island coasts with high dynamic of sea currents, where it is of interest to assess the impact of the introduction of advanced systems for the exploitation of sea wave renewable energy on marine ecosystems and coastal environments, characterized by high biodiversity but significantly vulnerable to the pressure of anthropic activities and to climate change effects.

Author Contributions: Conceptualization, methodology (F.B., C.M), Sea truth collection/processing \& validation (C. M., L.D.C., C.G. G.M., G.A.D.S.), resources, writing review and editing (F.B, C.M., G.S., M.V.S., All); supervision (F.B., C.M.). All authors have read and agreed to the published version of the manuscript.

Funding: This research was conducted within the framework of the Marine Hazard project (PONFESR 2020-2022) and multi-year national program of National Electric System Research (RdS) financed by the MISE (Ministry of Economic Development) for research and development activities in the electricity sector and to improve the cost-effectiveness, safety, and environmental compatibility, of energy production.

Data Availability Statement: Data sharing is not applicable to this article.

Acknowledgments: Acknowledgements to the ENEA station for climate observation Roberto Sarao of Lampedusa islands for administrative and technical support to the work in sea truth and EO data collection and pre-processing. In addition, the authors acknowledge the partnership agreement between ENEA and CNR-IBE for the CAL/VAL activity of the PRISMA sensor (PRISCAV project), supported by ASI.

Conflicts of Interest: The authors declare no conflict of interest. ENEA is not responsible for any use, even partial, of the contents of this document by third parties and any damage caused to third parties resulting from its use.

\section{References}

1.

2. Bidak, Laila M.M.; Heneidy, Selim Z.; Li, W.; Fakhry, Amal M.; El kenany, Eman T.; El Askary, Hesham M.; Elkareem, Mohamed S. Mediterranean Tapeweed Posidonia oceanica (L.) Delile, an Endangered Seagrass Species. Egypt. J. Bot. 2021, 61 (2), $335-348$.

3. Gnisci, V.; Cognetti De Martiis, S.; Belmonte, A.; Micheli, C; Piermattei, V.; Bonamano, S.; Marcelli, M. Assessment of the ecological structure of Posidonia oceanica (L.) Delile on the northern coast of Lazio, Italy (central Tyrrhenian, Mediterranean). Ital. Bot. 2020, 9, 1-19. doi: 10.3897/italianbotanist.9.46426

4. Madonia, A.; Caporale, G.; Penna, M.; Bonamano, S.; Marcelli, M. Assessment of the Photosynthetic Response of Posidonia oceanica (Linneaus) Delile, 1813 along a Depth Gradient in the Northern Tyrrhenian Sea (Latium, Italy). Geosciences 2021, 11, 202. https://doi.org/10.3390/geosciences11050202

5. Stramska, M.; Aniskiewicz, P. Recent Large Scale Environmental Changes in the Mediterranean Sea and Their Potential Impacts on Posidonia oceanica. Remote Sens. 2019, 11, 110. https://doi.org/10.3390/rs11020110

6. Giardina, F.; De Rubeis, P. Analisi della prateria a Posidonia oceanica (L.) Delile (Najadales, Potamogetonaceae) dell'isola di Lampedusa(AMP Isole Pelagie, Canale di Sicilia), Bollettino Accademia Gioenia Sci. Nat. 2012, 45 (375), 651-664, Catania 2012, ISSN $0393-7143$ 
7. Mannino, A.M.; Borfecchia, F.; Micheli, C. Tracking Marine Alien Macroalgae in the Mediterranean Sea: The Contribution of Citizen Science and Remote Sensing. J. Mar. Sci. Eng. 2021, 9, 288, https://doi.org/10.3390/jmse9030288 "

8. Petrocelli, A.; Cecere, E.; Portacci, G.; Micheli, C.; De Cecco, L.; Martini, S.; Borfecchia, F. Preliminary mapping of the alien seaweed Hypnea cornuta (Rhodophyta, Gigartinales) in the Mar Piccolo of Taranto (southern Italy, Mediterranean Sea). Biol. Mar. Mediterr. 2015, 22 (1), 44-45.

9. Boudouresque, C. F.; Blanfuné, A.; Pergent, G.; Thibaut, T. (2021). Restoration of Seagrass Meadows in the Mediterranean Sea: A Critical Review of Effectiveness and Ethical Issues. Water 2021, 13(8), 1034. https://doi.org/10.3390/w13081034.

10. Micheli, C.; Cupido, R.; Lombardi, C.; Belmonte, A.; Peirano, A. Changes in genetic structure of Posidonia oceanica at Monterosso al Mare (Ligurian Sea) and its resilience over a decade (1998-2009). Environ. Manage. 2012, 50, 598-606. doi.org/10.1007/s00267012-9917-3

11. Micheli, C.; D'Esposito, D.; Belmonte, A.; Peirano, A.; Valiante, L.M.; Procaccini, G. Genetic diversity and structure in two protected Posidonia oceanica meadows. Mar. Environ. Res. 2015, 109, 124-131. https://doi.org/10.1016/j.marenvres.2015.06.016.

12. Hossain, M.S.; Bujang, J.S.; Zakaria, M.H.; Hashim, M. The application of remote sensing to seagrass ecosystems: an overview and future research prospects. Int. J. Rem. Sensing 2015, 36(1), 61-114

13. Sciortino, M.; De Felice, M.; De Cecco, L.; Borfecchia, F. Remote sensing for monitoring and mapping Land Productivity in Italy: A rapid assessment methodology, CATENA 2020, 188,104375, ISSN 0341-8162, https://doi.org/10.1016/j.catena.2019.104375.

14. Borfecchia, F.; Cimbelli, A.; De Cecco, L.; Della Rocca, A. B.; Martini, S.; Barbini, R.; Colao, F.; Fantoni, R.; Palucci, A.; Ribezzo, R. Integrated remote sensing mission in the Venice Lagoon. Proceedings Volume 2959, Remote Sensing of Vegetation and Sea 1997, https://doi.org/10.1117/12.264266, Satellite Remote Sensing III, 1996, Taormina, Italy

15. Borfecchia, F.; Micheli, C.; Cibic, T.; Pignatelli, V.; De Cecco, L.; Consalvi, N.; Caroppo, C.; Rubino, F.; Di Poi, E.; Kralj M.; Del Negro P. Multispectral data by the new generation of high-resolution satellite sensors for mapping phytoplankton blooms in the Mar Piccolo of Taranto (Ionian Sea, southern Italy). Europ. J. Rem. Sens. 2019 52(1), 400-418, DOI: $10.1080 / 22797254.2019 .1625726$

16. Homolova, L.; Malenovsky, Z.; Clevers, J.G.P.W.; Garcia-Santos, G.; Schaepman, M. E. Review of optical-based remote sensing for plant trait mapping. Ecological Complexity 2013, 15, 1-16

17. Borfecchia, F.; Crinò, P.; Correnti, A.; Farneti, A.; De Cecco, L.; Masci, D.; Blasi, L.; Iantosca, D.; Pignantelli, V.; Micheli, C. Assessing the Impact of Water Salinization Stress on Biomass Yield of Cardoon Bio-Energetic Crops through Remote Sensing Techniques. Resources 2020, 9 (10), 124, https://doi.org/10.3390/resources9100124

18. Pollino, M.; Cavallini, A.; Caiaffa, E.; Borfecchia, F.; De Cecco, L. Geomatics to Analyse Land Transformation in Mozambique? The Nacala Corridor Case Study. In: Bevilacqua, C.; Calabrò, F.; Della Spina, L. (eds) New Metropolitan Perspectives. NMP 2020. Smart Innovation, Systems and Technologies, vol 178. Springer, Cham, 2020. https://doi.org/10.1007/978-3-030-48279-4_157

19. Borfecchia, F.; Frezzotti, M. Satellite Image Mosaic of the Terra Nova Bay Area, Victoria Land, Antarctica. MEM. SOC. GEOL. IT 1991, 46, 521-523.

20. Pham, T.D.; Xia, J.; Ha, N.T.; Bui, D.T.; Le, N.N.; Tekeuchi, W. A Review of Remote Sensing Approaches for Monitoring Blue Carbon Ecosystems: Mangroves, Seagrasses and Salt Marshes during 2010-2018. Sensors 2019, 19, 1933, https://doi.org/10.3390/s19081933

21. Borfecchia, F.; Consalvi, N.; Micheli, C.; Carli, F. M.; Cognetti De Martiis, S.; Gnisci, V.; Piermattei, V.; Belmonte, A.; De Cecco, L.; Bonamano, S.; Marcelli, M. Landsat 8 OLI satellite data for mapping of the Posidonia oceanica and benthic habitat of coastal ecosystems. Int. J. Rem. Sens. 2018, 39 (18), 1-28.

22. Medina-Lopez, E. Machine Learning and the End of Atmospheric Corrections: A Comparison between High-Resolution Sea Surface Salinity in Coastal Areas from Top and Bottom of Atmosphere Sentinel-2 Imagery. Remote Sens. 2020, $12,2924$. https://doi.org/10.3390/rs12182924

23. Colomer, J.; Serra, T. The World of Edges in Submerged Vegetated Marine Canopies: From Patch to Canopy Scale. Water 2021, 13, 2430. https://doi.org/10.3390/w13172430

24. Bracco, G.; Giorcelli, E.; Giorgi, G.; Mattiazzo, G.; Passione B.; Raffero M.; Vissio, G. Performance assessment of the full scale ISWEC system, IEEE International Conference on Industrial Technology (ICIT) 2015, 2499-2505, doi: 10.1109/ICIT.2015.7125466.

25. Borfecchia, F.; Micheli, C.; Belmonte, A.; De Cecco, L.; Gomez, C.; Bracco, G.; Mattiazzo, G.; Struglia, M. V.; Sannino, G.; Valutazione dell'impatto ambientale del sistema ISWEC tramite tecniche integrate di Remote Sensing ed in situ. Proceeedings ASITA 2016, 67-80, ISBN 978-88-941232-6-5, 8-10 Novembre 2016, Cagliari.

26. Borfecchia, F.; Micheli, C.; De Cecco, L. Stima degli impatti sugli ecosistemi costieri da impianti Waves energy tramite tecniche di remote sensing, ENEA Report RdS/PAR2014/224, Settembre 2015

27. Borfecchia, F.; Micheli, C.; Belmonte, A.; De Cecco, L.; Sannino, G.; Bracco, G.; Mattiazzo, G.; Struglia, M.V. Impact of ISWEC sea wave energy converter on Posidonia oceanica meadows assessed by satellite remote sensing in the coastal areas of Pantelleria island. EGU General Assembly 2016, 17-22 April, 2016, Vienna Austria, id. EPSC2016-16787

28. Li, F.; Jupp, D.L.B.; Schroeder, T.; Sagar, S.; Sixsmith, J.; Dorji, P. Assessing an Atmospheric Correction Algorithm for Time Series of Satellite-Based Water-Leaving Reflectance Using Match-Up Sites in Australian Coastal Waters. Remote Sens. 2021, 13, 1927. https://doi.org/10.3390/rs13101927

29. Cui, L.; Li, G.; Ren, H-; He, L.; Liao, H.; Ouyang, N.; Zhang, Y. Assessment of atmospheric correction methods for historical Landsat TM images in the coastal zone: A case study in Jiangsu, China. European Journal of Remote Sensing; Cagiari 2014, 47(1), 701-716. DOI:10.5721/EuJRS20144740. 
30. Holloway, J.; Mengersen, K. Statistical Machine Learning Methods and Remote Sensing for Sustainable Development Goals: A Review. Remote Sens. 2018, 10, 1365. https://doi.org/10.3390/rs10091365

31. Kima, Y. H.; Imb, J.; Hac, H. K.; Choid, J.-K.; Ha, S. Machine learning approaches to coastal water quality monitoring 32. using GOCI satellite data. GIScience E Remote Sensing 2014, 51(2), 158-174.

33. Pollino, M.; Cappucci, S.; Giordano, L.; Iantosca, D.; De Cecco, L.; Bersan, D.; Rosato, V.; Borfecchia, F. Assessing earthquakeinduced urban rubble by means of multiplatform remotely sensed data. ISPRS International Journal of Geo-Information 2020, 9 (4), 262

34. Lary, D. J.; Alavi, A. H.; Gandomi, A. H.; Walker, A. L. Machine learning in geosciences and remote sensing. Geoscience Frontiers 2016, 7(1), 3-10.

35. Bakirman, T.; Gumusay, M. U. Assessment of Machine Learning Methods for Seagrass Classification in the Mediterranean. Baltic J. Modern Computing 2020, 8 (2), 315-326, https://doi.org/10.22364/bjmc.2020.8.2.07.

36. Effrosynidis, D.; Arampatzis, A.; Sylaios, G. Seagrass detection in the mediterranean: A supervised learning approach. Ecological Informatics 2018, 48, 158-170, https://doi.org/10.1016/j.ecoinf.2018.09.004

37. Micheli, C.; Borfecchia, F.; De Cecco, L.; Martini, S.; Ceriola, G.; Bollanos, S.; Vlachopoulos, G.; Valiante, L. M.; Fresi, E.; Campbell, G. Seagrass monitoring by remote sensing in the context of biodiversity conservation. Rapp. Comm. Int. Mer. Medit 2010, 39, 778-779

38. Traganos, D.; Aggarwal, B.; Poursanidis, D.; Topouzelis, K.; Chrysoulakis, N.; Reinartz, P. Towards Global-Scale Seagrass Mapping and Monitoring Using Sentinel-2 on Google Earth Engine: The Case Study of the Aegean and Ionian Seas. Remote Sens. 2018, 10, 1227. https://doi.org/10.3390/rs10081227.

39. Schwieder, M.; Leitao, P.J.; Suess, S.; Senf, C.; Hostert, P. Estimating Fractional Shrub Cover Using Simulated EnMAP Data: A Comparison of Three Machine Learning Regression Techniques. Remote Sens. 2014, 6, $3427-3445$. https://doi.org/10.3390/rs6043427

40. Pergent, G.; Pergent-Martini, C.; Boudouresque, C. F. Utilisation De L'herbier A Posidonia Oceanica Comme Indicateur Biologique De La Qualite Du Milieu Littoral En Mediterranee Etat Des Connaissances. MESOGEE 1995, 54, 3-27

41. Tonielli, T.; Innangi, S.; Budillon, F.; Di Martino, G.; Felsani, M.; Giardina, F.; Innangi, M.; Filiciotto F. Distribution of Posidonia oceanica (L.) Delile meadows around Lampedusa Island (Strait of Sicily, Italy), Journal of Maps 2016, 12(1), 249-260, DOI: 10.1080/17445647.2016.1195298

42. Pepe, M.; Pompilio, L.; Gioli, B.; Busetto, L.; Boschetti, M. Detection and Classification of Non-Photosynthetic Vegetation from PRISMA Hyperspectral Data in Croplands. Remote Sens. 2020, 12, 3903. https://doi.org/10.3390/rs12233903

43. Ha, N.T.; Manley-Harris, M.; Pham, T.D.; Hawes, I. A Comparative Assessment of Ensemble-Based Machine Learning and Maximum Likelihood Methods for Mapping Seagrass Using Sentinel-2 Imagery in Tauranga Harbor, New Zealand. Remote Sens. 2020, 12, 355. https://doi.org/10.3390/rs12030355

44. Busetto, L., Ranghetti, L. (2020) prismaread: A tool for facilitating access and analysis of PRISMA L1/L2 hyperspectral imagery v1.0.0, URL: https://lbusett.github.io/prismaread/, doi: https://doi.org/10.5281/zenodo.4019081

45. Loisel, H.; Vantrepotte, V.; Jamet, C.; Ngoc, D. D. Challenges and New Advances in Ocean Color Remote Sensing of Coastal Waters.Topics in Oceanography, Prof. Enrico Zambianchi (Ed.), InTech 2013 DOI: 10.5772/56414. https://www.intechopen.com/books/topics-in-oceanography/challenges-and-new-advances-in-ocean-color-remote-sensing-ofcoastal-waters

46. Vanhellemont Q.; Ruddick K. , Acolite For Sentinel-2: Aquatic Applications of MSI Imagery. proceedings of the 2016 ESA Living Planet Symposium, Prague, Czech Republic, 9-13 May 2016, ESA Special Publication SP-740

47. Vanhellemont, Q. Adaptation of the dark spectrum fitting atmospheric correction for aquatic applications of the Landsat and Sentinel-2 archive. Remote Sens. Environ. 2019, 225, 175-192.

48. Marcello, J.; Eugenio, F.; Martín, J.; Marqués, F. Seabed Mapping in Coastal Shallow Waters Using High Resolution Multispectral and Hyperspectral Imagery. Remote Sens. 2018, 10, 1208. https://doi.org/10.3390/rs10081208

49. Richter, R.; Schlapfer, D.; Muller, A. An automatic atmospheric correction algorithm for visible/NIR imagery. Int. J. Remote Sensing 2006, 27, 2077-2085.

50. Wolters, E.; Toté, C.; Sterckx, S.; Adriaensen, S.; Henocq, C.; Bruniquel, J.; Scifoni, S.; Dransfeld, S. iCOR Atmospheric Correction on Sentinel-3/OLCI over Land: Intercomparison with AERONET, RadCalNet, and SYN Level-2. Remote Sens. 2021, $13,654$. https://doi.org/10.3390/rs13040654

51. 